Portland State University

PDXScholar

$12-18-2019$

\title{
The Combined Effects of Parent and Teacher Involvement on the Development of Adolescents' Academic Engagement
}

Nicolette Paige Rickert

Portland State University

Follow this and additional works at: https://pdxscholar.library.pdx.edu/open_access_etds

Part of the Education Commons, and the Psychology Commons

Let us know how access to this document benefits you.

Recommended Citation

Rickert, Nicolette Paige, "The Combined Effects of Parent and Teacher Involvement on the Development of Adolescents' Academic Engagement" (2019). Dissertations and Theses. Paper 5411.

https://doi.org/10.15760/etd.7284

This Dissertation is brought to you for free and open access. It has been accepted for inclusion in Dissertations and Theses by an authorized administrator of PDXScholar. Please contact us if we can make this document more accessible: pdxscholar@pdx.edu. 
The Combined Effects of Parent and Teacher Involvement on the Development of Adolescents' Academic Engagement

by

Nicolette Paige Rickert

A dissertation submitted in partial fulfillment of the requirements for the degree of

Doctorate of Philosophy

in

Applied Psychology

Dissertation Committee:

Ellen A. Skinner, Chair

Thomas A. Kindermann

Joel S. Steele

Pat Burk

Portland State University

2020 
(C) 2019 Nicolette Paige Rickert 
Abstract i

\begin{abstract}
The current dissertation includes two related studies designed to examine the combined effects of parent and teacher involvement on the development of adolescents' academic engagement as they transition to middle school. Previous studies have demonstrated the positive, individual effects of parent and teacher warm involvement on adolescents' engagement in school. However, this research is limited in its focus on only one social partner. Adolescent development is embedded within multiple, dynamic systems, necessitating the examination of both parent and teacher influences. The few studies that have examined parents and teachers together suggest that their combined effects are both cumulative (additive) and mediated (one partner exerts its effects via the other partner). However, these studies have largely been cross-sectional in nature, posing limitations with regard to understanding changes in the effects of adult supports and feedback effects of adolescents on their parents and teachers.

To address these limitations and contribute to further research on the combined effects of parent and teacher warm involvement, two longitudinal studies were conducted. Study 1 used dynamic path analyses to frame an examination of the combined influence of parent and teacher warm involvement on the development of adolescents' academic engagement and the reciprocal effects of adolescent engagement on adults' continued involvement across a single school year for $5^{\text {th }}, 6^{\text {th }}$, and $7^{\text {th }}$ grade students. Study 2 utilized mediation path analyses to determine if the combined effects of parent and teacher warm involvement on adolescents' engagement were similarly or differentially explained by an engendered sense of relatedness to others across a single school year for $3^{\text {rd }}, 4^{\text {th }}, 5^{\text {th }}$, and $6^{\text {th }}$ grade students. In both studies, evidence was found for
\end{abstract}




\begin{abstract}
ii
the cumulative effects of both parents and teachers on students' academic engagement, along with the reciprocal effects of adolescents on their parents and teachers (Study 1), and the importance of a sense of relatedness as a mediator between warn involvement and engagement (Study 2).
\end{abstract}




\section{Dedication}

This dissertation is dedicated to three important persons in my life:

I dedicate this dissertation to Jordan Futran - surviving graduate school would not have been possible (or at least not probable) without you. Thank you for listening when I wanted to be heard, pushing when I needed to be motivated, focusing on the little things when I was overwhelmed, and, of course, feeding me when I was hangry.

This dissertation is also dedicated to my parents, Mark and Susan Rickert. Your continual acceptance, love, and involvement throughout my academic career were part of my inspiration for this dissertation.

Finally, this dissertation is dedicated to the other half of my inspiration for this project - the teachers across my life. 


\section{Acknowledgements}

I would like to thank my advisor, Dr. Ellen Skinner, for her guidance and confidence throughout this process as well as her excellent modeling of teacher warm involvement. I would also like to acknowledge the assistance and valuable input from the rest of my committee, Drs. Thomas Kindermann, Joel Steele, and Pat Burk. Thank you to my lab mates (former and current), peer mentor, cohort, and friends for their instrumental and emotional support. Finally, I would like to thank my family for encouraging me in all my endeavors. 


\section{Table of Contents}

Chapter Chapter Title/Subtitle

Abstract

Dedication

Acknowledgements

List of Tables

List of Figures

1 Introduction

2 Literature Review

Student Academic Engagement

Trends over the transition to middle school

Sense of Relatedness

Individual Effects of Adult Social Partners

Parent involvement

Findings from studies of parent involvement

Teacher involvement

Findings from studies of teacher involvement

Limitations of studies on the individual effects of parent and teacher involvement

Combined Effects of Adult Social Partners

Cumulative effects

Mediated effects

Importance and limitations of combined effects studies

Reciprocal Effects of Adolescent Engagement

Summary
Page

i

iii

iv

viii

ix

1

Individual Effects of Parent and Teacher Involvement on Student Engagement

Parent involvement and student engagement

Teacher involvement and student engagement

Combined Effects of Parent and Teacher Involvement 
Cumulative effects of parents and teachers 28

Mediated effects of parents and teachers 28

Reciprocal Effects of Student Engagement 29

Current Study 31

Method 32

$\begin{array}{ll}\text { Participants } & 32\end{array}$

Design and Procedure $\quad 32$

Measures $\quad 32$

Perceived parent warm involvement 33

Perceived teacher warm involvement 33

Adolescent academic engagement 33

Results 34

Missing Data 34

Descriptive Analyses $\quad 34$

Path Models $\quad 35$

Behavioral engagement 36

Emotional engagement 38

Discussion 40

Limitations and Future Directions $\quad 42$

Implications 44

$4 \quad$ Study $2 \quad 46$

Combined Effects of Parent and Teacher Involvement 47

Sense of Relatedness as a Mediator 48

Current Study 51

Method 52

Participants $\quad 52$

Design and Procedure $\quad 52$

Measures $\quad 52$

Perceived parent warm involvement 52

Perceived teacher warm involvement 53

Sense of relatedness 53 
Table of Contents vii

Behavioral engagement 53

Emotional engagement 53

Results $\quad 54$

Missing Data $\quad 54$

Descriptive Analyses $\quad 54$

Process Path Models $\quad 56$

Behavioral engagement $\quad 57$

Emotional engagement $\quad 57$

Discussion $\quad 59$

Limitations $\quad 60$

Future Directions $\quad 61$

Educational Implications $\quad 63$

$\begin{array}{lll}5 & \text { Discussion } & 64\end{array}$

Summary of Dissertation Studies $\quad 64$

Strengths of the Current Studies $\quad 64$

Limitations and Future Directions 66

Implications for Interventions $\quad 69$

Nest Steps in Examining Students’ Complex Social Ecologies 70

Contextualized effects $\quad 71$

Multiple, changing contexts $\quad 71$

Proximal interactions $\quad 72$

Higher-order contextual influences $\quad 73$

Person- and pattern-centered analyses $\quad 74$

Future research plans $\quad 74$

References $\quad 76$

Appendix A: Measures $\quad 86$ 


\section{List of Tables}

Table Title Page

$2.1 \quad$ Reviewed Studies of Combined Effects of Parent and Teacher 18
Involvement

3.1 Descriptives and Correlations among Variables for $5^{\text {th }}, 6^{\text {th }}$, and $7^{\text {th }}$ Grade 36 Students

4.1 Descriptive Statistics and Correlations among Variables for $3^{\text {rd }}, 4^{\text {th }}, 5^{\text {th }}, \quad 55$ and $6^{\text {th }}$ Grade Students

4.2 Model Comparisons for Unconstrained vs. Constrained Effects across 57 Grades 


\section{List of Figures}

Figure Title Page

\begin{tabular}{lll}
\hline $2.1 \quad$ Bioecological model of adolescent development inspired by & 14
\end{tabular} Bronfenbrenner \& Morris (1998)

3.1 Proposed path model of the combined, dynamic effects of parent and 25 teacher involvement and the reciprocal effects of adolescent academic engagement

3.2 Constrained effects path model for behavioral engagement 37

3.3 Constrained effects alternative path model for behavioral engagement 38

3.4 Constrained effects path model for emotional engagement 39

3.5 Constrained effects alternative path model for emotional engagement 40

4.1 Process model account of involvement, relatedness, and academic 49 engagement through the self-system process model of motivation (Connell \& Wellborn, 1991)

4.2 Constrained effects mediation model for behavioral engagement 58

4.3 Constrained effects mediation model for emotional engagement 59 


\section{Chapter 1: Introduction}

Adolescent academic engagement has marked a popular area of educational and developmental research in part due to the many positive outcomes associated with it, including attendance, retention, grades, achievement, and resilience (Fredricks, Blumenfeld, \& Paris, 2004; Raftery, Grolnick, \& Flamm, 2012). Parents, teachers, and researchers alike seek to optimize the development of adolescents' engagement with academic tasks (Baltes, Reese, \& Nesselroade, 1977). However, as adolescents transition from elementary to middle schools, normative declines are seen in their academic engagement (Wigfield et al., 2015). According to stage-environment fit theory (Eccles et al., 1993), this is due to the differences in contextual affordances offered by elementary schools as opposed to middle schools, wherein middle school environments are not developmentally attuned to adolescents' developmental needs. Fortunately, adolescents' parents and teachers can help to mitigate these normative declines, supporting students' engagement in school in developmentally appropriate ways through their warm, supportive involvement and close relationships (e.g., Bempechat \& Shernoff, 2012; Quin, 2017; Raftery et al., 2012; Roorda, Koomen, Spilt, \& Oort, 2011). As key adult social partners with daily opportunities to interact with and guide adolescents, parents and teachers hold a significant position and sway in adolescents' academic lives.

Yet, previous studies on the beneficial effects of parents and of teachers have remained largely isolated from each other. In both areas, researchers typically examine only one or the other social partner. As Bronfenbrenner argued in his bioecological model (Bronfenbrenner \& Morris, 1998), adolescent development is embedded in multiple 
systems, including both home and school microsystems, and is shaped by daily proximal processes with both parents and teachers. Studying the effects of only one of these adult social partners ignores the simultaneous developmental processes occurring with the other, resulting in theories, methods, and analyses of the development of adolescent engagement that are limited in scope and understanding. Without studying the effects of both parents and teachers, research cannot fully explain or improve the dynamic, holistic experience of adolescents' academic lives. Thus, the current and future studies need to examine theoretically and analytically the combined, simultaneous effects of parents and teachers on the development of adolescents' academic engagement across the transition to middle school.

As such, the current dissertation examined the combined effects of parents and teachers in two longitudinal studies across the transition to middle school. Study 1 used a series of path models to examine the dynamic influence of parent and teacher warm involvement on the development of adolescents' academic engagement as well as the reciprocal effects of adolescent engagement on adults' continued involvement. Study 2 utilized a series of mediation path analyses to determine the similar or differential explanatory means through which parent and teacher warm involvement impact adolescents' academic engagement, specifically by examining students' sense of relatedness to their adult social partners.

The goals of this dissertation were to review literature examining the individual and combined effects of parent and teacher warm involvement on the optimal development of adolescents' academic engagement; explore the combined effects of 
parents and teachers through two related but analytically complementary studies; and discuss the potential implications of these results with respect to adolescents' academic engagement, applied intervention and prevention efforts, and theoretical and analytical suggestions for future research. In line with these goals, the current dissertation is organized in five chapters. Chapter 2 provides a Literature Review of adolescents' academic engagement and trends over the transition to middle school, individual effects of parents' and teachers' warm involvement, combined effects of parents and teachers, and the reciprocal effects of adolescents' academic engagement. Chapters 3 and 4 detail Study 1 and Study 2, respectively, with an introduction, method, results, and discussion. Finally, Chapter 5 summarizes the dissertation studies and discusses their strengths, limitations, and future directions for research. 


\section{Chapter 2: Literature Review}

The following review of the literature covers the main constructs of interest across the two studies of this dissertation. These constructs include the focal target of the development of student academic engagement, as well as the separate and combined effects of parent and teacher warm involvement on student academic engagement, and the reciprocal effects of student engagement on parent and teacher involvement.

\section{Student Academic Engagement}

A wealth of research has focused on the concept of academic engagement, because it is tied to resilience, attendance and retention, and grades and achievement (Christenson, Reschly, \& Wylie, 2012; Fredricks, Blumenfeld, \& Paris, 2004; Raftery, Grolnick, \& Flamm, 2012). However, academic engagement has been conceptualized in different ways across studies and lines of research. In light of these differences, it is important for researchers to clearly define their chosen conceptualization of academic engagement. The current studies draw upon a motivational conceptualization of engagement, defined as students' active, energetic, enthusiastic participation with learning activities in school. From this perspective, engagement is the visible manifestation of students' motivation, that is, their energy (i.e., enthusiasm, interest), direction (i.e., purpose, focus), and persistence (i.e., effort, endurance) with academic tasks and challenges (Skinner, 2016; Skinner, Kindermann, Connell, \& Wellborn, 2009; Skinner \& Pitzer, 2012). It is this quality of student engagement that may explain the positive associations between engagement and learning. The current studies focus specifically on two types of academic engagement: behavioral and emotional. Behavioral 
engagement involves students' involvement and participation in academic tasks, including their attentiveness, initiative, and effort, while emotional engagement refers to students' positive, affective reactions to academic work such as their enjoyment and interest(Fredricks et al., 2004, Skinner, 2016).

Interest in academic engagement stems not only from its associations with multiple positive academic outcomes but also from its malleability. Engagement is not considered a motivational trait but a state that can be shaped by the dynamic interactions between adolescent students and their academic tasks, social partners, and academic contexts both in the short and long term (Fredricks et al., 2004). As such, the motivational conceptualization of engagement also focuses on facilitators of engagement, explanatory or causal components leading to and separate from academic engagement (Skinner, 2016; Skinner \& Pitzer, 2012). While engagement is shaped by many different factors, chief among them are the quality of adolescents' relationships with their parents and teachers. Thus, the key facilitators of engagement included in the current studies are the social contexts and relationships that adolescents experience on a daily basis, specifically parent and teacher warm, supportive involvement in students' academic lives.

Trends over the transition to middle school. Unfortunately, many students struggle to maintain their engagement, motivation, and achievement in school as they transition contexts from elementary to middle schools. Numerous studies have found that as adolescents make this transition, their engagement with academic tasks declines (Wigfield et al., 2015). According to stage-environment fit theory, these changes are a result of a mismatch between the developmental needs of adolescent students and the 
environmental affordances provided by middle schools (Eccles et al., 1993). When students' developmental needs, such as feelings of relatedness, competence, and autonomy, are met by their academic environments, as is often the case within elementary schools, their intrinsic motivation will be supported and academic engagement will flourish. However, when these needs are not met in a developmentally appropriate way, as seen in controlling, performance-oriented, impersonal middle schools, students' academic motivation will not be supported, resulting in declines in engagement and potentially increases in disaffection, or withdrawal, dejection, or apathy toward academic work.

When adolescents transition to middle school, they move from close-knit, singleteacher classrooms with mastery goals, allowances for student choice, and cognitively demanding schoolwork in elementary schools to impersonal, multiple classes with performance goals, higher levels of teacher control, and less rigorous assignments in middle schools (Anderman \& Mueller, 2010; Eccles \& Roeser, 2015; Wigfield et al., 2015). Longitudinal, quasi-experimental designs examining differences between students attending $\mathrm{K}-8^{\text {th }}$ schools versus $\mathrm{K}-6^{\text {th }}$ and transitioning to middle schools offer evidence for the negative consequences of developmental mismatches of middle schools, including decreases in GPAs, math scores, participation in extracurriculars, and girls' self-esteem (Anderman \& Mueller, 2010). Studies of adolescents' transition from elementary to middle schools have also found evidence for declines in competence expectations for English, decreases in intrinsic motivation and increases in extrinsic motivation, and declines in mastery goal orientations (Anderman \& Mueller, 2010). Thus, as adolescents 
transition from supportive elementary schools to developmentally inappropriate middle schools, their engagement and motivation decline. Fortunately, research suggests that these normative declines may be offset or mitigated through a sense of relatedness engendered by the contextual supports offered by adolescents' adult social partners: parents and teachers.

\section{Sense of Relatedness}

Numerous motivational theories of development focus on how processes of the self can fuel students' engagement with academic tasks and challenges. One key selfprocess is a sense of relatedness or connectedness and belonging to others (Martin \& Dowson, 2009). Most notably, self-determination theory posits that all individuals have a need to feel connected with those around them - that they belong and are worthy of love and respect (Ryan \& Deci, 2017). Further, the self-system process theory of motivational development and research suggest that when this need for relatedness and emotional security is fulfilled, adolescents are more likely to respond with active participation, enthusiastic interest, and tenacious persistence when faced with tasks and challenges in the classroom (Connell \& Wellborn, 1991; Furrer \& Skinner, 2003; King, 2015). This is in part because through a sense of relatedness to others, not only do adolescents develop positive views of themselves (i.e., self-worth, self-esteem), but they also observe, learn, and internalize the educational beliefs and values of their social partners (i.e., achievement goal orientations, causal attributions). Beyond these two theories, several other motivational theories acknowledge the importance of relatedness in students' academic lives (e.g., achievement goal theory, attribution theory, expectancy-value 
theory, self-efficacy theory, self-worth motivation theory; Martin \& Dowson, 2009). Therefore, a crucial leverage point to intervening and sustaining adolescents' academic engagement is by fulfilling their need for relatedness and emotional security with close social partners. A key facilitator to creating this sense of belonging and connection is through the warm support and involvement offered by adolescents' parents and teachers (Connell \& Wellborn, 1991).

\section{Individual Effects of Adult Social Partners}

As mentioned above, the key facilitators of student academic engagement highlighted in the current studies are the social contexts of parents and teachers and their relationships with adolescents, characterized by warm involvement in their academic lives. Warm involvement seems to play a foundational role because of its ties to relatedness and belonging (Connell \& Wellborn, 1991). These are core aspects of interpersonal relationships, which are featured in many achievement motivation theories (e.g., attribution theory, self-worth motivation theory, self-determination theory; Martin \& Dowson, 2009). It is through these secure, interpersonal relationships with parents and teachers that students feel supported to explore, motivated to work hard on academic tasks, and positively cope with academic challenges (Wentzel, 2016).

Parent involvement. Parent involvement has been defined and conceptualized in a variety of ways. For example, Grolnick, Friendly, and Bellas (2009) define parent involvement as “...the provision of tangible resources (e.g., time, attention) as well as relationship characteristics (e.g., emotional support, warmth) that provide children with the psychological resources essential for motivation in school” (p. 281). They further 
differentiate between behavioral involvement (e.g., attending parent-teacher conferences), cognitive or intellectual involvement (e.g., introducing students to cognitive activities such as books), and personal involvement (e.g., caring about school). In a review of 13 studies examining the effects of parent involvement, Gonzalez-DeHass, Willems, and Holbein (2005) included studies that conceptualized parent involvement as participating in parent-teacher conferences and school activities, engaging in schoolrelated activities at home or extracurricular activities, assisting students in the selection of courses, keeping in touch with their academic progress and reacting to their grades, imparting values such as the importance of effort and academic success, or a combination of these. Pomerantz and Moorman (2010) differentiate between school-based parent involvement (e.g., attending school meetings, talking with teachers) and home-based parent involvement (e.g., helping students with academic tasks, talking with students about school issues). Given the multitude of definitions for parent involvement, the current studies draw on the interpersonal aspects of previous definitions to specifically conceptualize parental involvement as warm, supportive relationships between parents and adolescents characterized by knowledge, care, and the availability to assist students with their academic experiences and feelings.

Findings from studies of parent involvement. Numerous reviews of the literature have found positive effects of high quality, supportive parent-adolescent relationships (Bempechat \& Shernoff, 2012; Upadyaya \& Salmela-Aro, 2013); authoritative parenting characterized by responsiveness and demandingness (Bempechat \& Shernoff, 2012; Raftery et al., 2012); parental mastery-orientations (Upadyaya \& Salmela-Aro, 2013); 
and parental behavioral and cognitive involvement (Grolnick et al., 2009; Upadyaya \& Salmela-Aro, 2013) on adolescents' academic motivation outcomes, including school engagement, academic competence, grades, and likelihood of graduating from high school. This research suggests that when parents are warm and emotionally supportive, responsive and interested in their adolescents' academic needs, and involved at school and home, adolescents are more motivated in school and academically engaged. These positive associations may in part be due to a sense of relatedness and belonging that adolescents perceive from their involved parents (Martin \& Dowson, 2009) and a sense of security and support to explore, exert themselves, fail, and try again (Wentzel, 2016). In spite of this, some evidence suggests that compared to relationships with younger children, parental behavioral involvement (e.g., attending school activities) declines during the adolescent years (Spera, 2005) and that parent-adolescent relationships tend to be characterized by mild conflict and less closeness (Smetana, Campione-Barr, \& Metzger, 2006; Steinberg \& Morris, 2001). Thus, the transition to middle school is a particularly important time to examine the effects of parents and their involvement.

Teacher involvement. Building on research on parental involvement, studies of teacher involvement have largely focused on teacher-student relationships, such as the quality of these interpersonal relationships as close, safe, and trusting; time spent with students; expressions of affection; enjoying student interactions; and dedicating resources to students (Skinner \& Belmont, 1993; Wentzel, 2010). Studies have also focused on teachers' pedagogical caring, which includes teachers modeling caring behavior, discussing perspective-taking with students, and encouraging students (Noddings, 1992) 
in addition to students' perceptions of their teachers as caring about their students as both individuals and learners (Wentzel, 1997). Similar to parent involvement, the current studies conceptualize teacher involvement as warm and supportive teacher-student relationships based upon teachers' knowledge, affection, and availability to interact with adolescents in the classroom.

Findings from studies of teacher involvement. Research suggests that teacher involvement has positive impacts on their adolescent students' motivational outcomes. Two meta-analyses found that positive affective (Roorda, Koomen, Spilt, \& Oort, 2011) and better-quality teacher-student relationships (Quin, 2017) are positively related to adolescents' school engagement. Reviews of the literature have also demonstrated that close, emotionally supportive teacher-student relationships are associated with such positive outcomes as adolescents' perceived control, autonomy, self-esteem (Wentzel, 2016; Wigfield et al., 2015), and engagement (Pianta, Hamre, \& Allen, 2012; Upadyaya \& Salmela-Aro, 2013). In addition, teacher support and teachers' modeling of their own engagement have been positively associated with their students' academic engagement (Upadyaya \& Salmela-Aro, 2013). Thus, as teachers demonstrate their interest in students and warmth and affection for them, adolescents respond with feelings of competence, support, and engagement in learning. However, there tend to be fewer close teacherstudent relationships across the transition to middle school as teachers have more classes with higher enrollments (Eccles \& Roeser, 2015), another reason why it is important to study the effects of adult involvement as adolescents transition to middle school. 


\section{Limitations of studies on the individual effects of parent and teacher}

involvement. Separate lines of research on parent and teacher involvement have demonstrated their importance in bolstering adolescent engagement. However, these discrete lines of research are not without their limitations. Most of the work examining the individual effects of parent and teacher involvement has been cross-sectional. In fact, only 13 of the 46 studies examined in Quin's (2017) meta-analysis of teacher-student relationships were longitudinal. Without longitudinal data, these studies cannot determine temporal precedence, predict change over time, or examine changes in the impacts of parent and teacher involvement on adolescents' motivational outcomes. In addition, because these studies only examine one social partner at a time, they are not able to reveal the combined, similar, or differential effects of both parents and teachers, the two adult social partners that adolescents interact with on a daily basis. Instead, these studies modeled only one aspect of students' complex social ecologies - parents or teachers.

\section{Combined Effects of Adult Social Partners}

Although previous research on the individual effects of parent or teacher involvement find positive associations with adolescents' academic engagement, these studies are restricted in their focus on only one social partner. According to the bioecological model of human development (Bronfenbrenner \& Morris, 1998), adolescents develop within multiple systems of interacting social partners and contexts (see Figure 2.1 for an example). At the most focal level exist adolescents' microsystems or "Pattern[s] of activities, social roles, and interpersonal relations experienced by the developing person in a given face-to-face setting with particular physical, social, and 
symbolic features that invite, permit, or inhibit engagement in sustained, progressively more complex interaction with, and activity in, the immediate environment" (Bronfenbrenner \& Morris, 1998, p. 1013). The home constitutes a microsystem in which adolescents engage in "proximal processes" with their parents daily, defined as reciprocal interactions between the adolescent and a social partner that occur on a regular basis and become more complex over time (Bronfenbrenner \& Morris, 1998). The school also constitutes a microsystem where adolescents frequently participate in proximal processes with their teachers.

By neglecting the multiple systems in which adolescent development is embedded, research is limited to understanding only a single piece of the puzzle of adolescent development and academic engagement. However, if parents, teachers, and researchers want to optimize adolescents' development (Baltes, Reese, \& Nesselroade, 1977), they will need to consider adolescents' complex social ecologies to understand the combined effects of parent and teacher involvement. For example, it is possible that the effects of parents and teachers are cumulative, wherein each exerts unique impacts on adolescents' academic engagement above and beyond the other social partner. Such effects would suggest that students need support from both their parents and their teachers in order to reach optimal levels of engagement. It is also possible that parent and teacher effects might be contextualized or amplifying where perhaps the effects of teachers depend on the strength of parents' support. Mediated effects are another possibility in which, for example, the impact of parents on adolescents is explained by a third, mediating variable - teachers' involvement. Contextualized and mediated effects 
like these would suggest that it is not possible to gauge the effects of one social partner without knowledge about the other partner. Therefore, the current studies seek to draw upon the bioecological model and highlight its developmental features by simultaneously examining two important social ecologies in which adolescents are embedded, changes in these social ecologies over the middle school years, and the reciprocal nature of adolescents' proximal processes with parents and teachers.

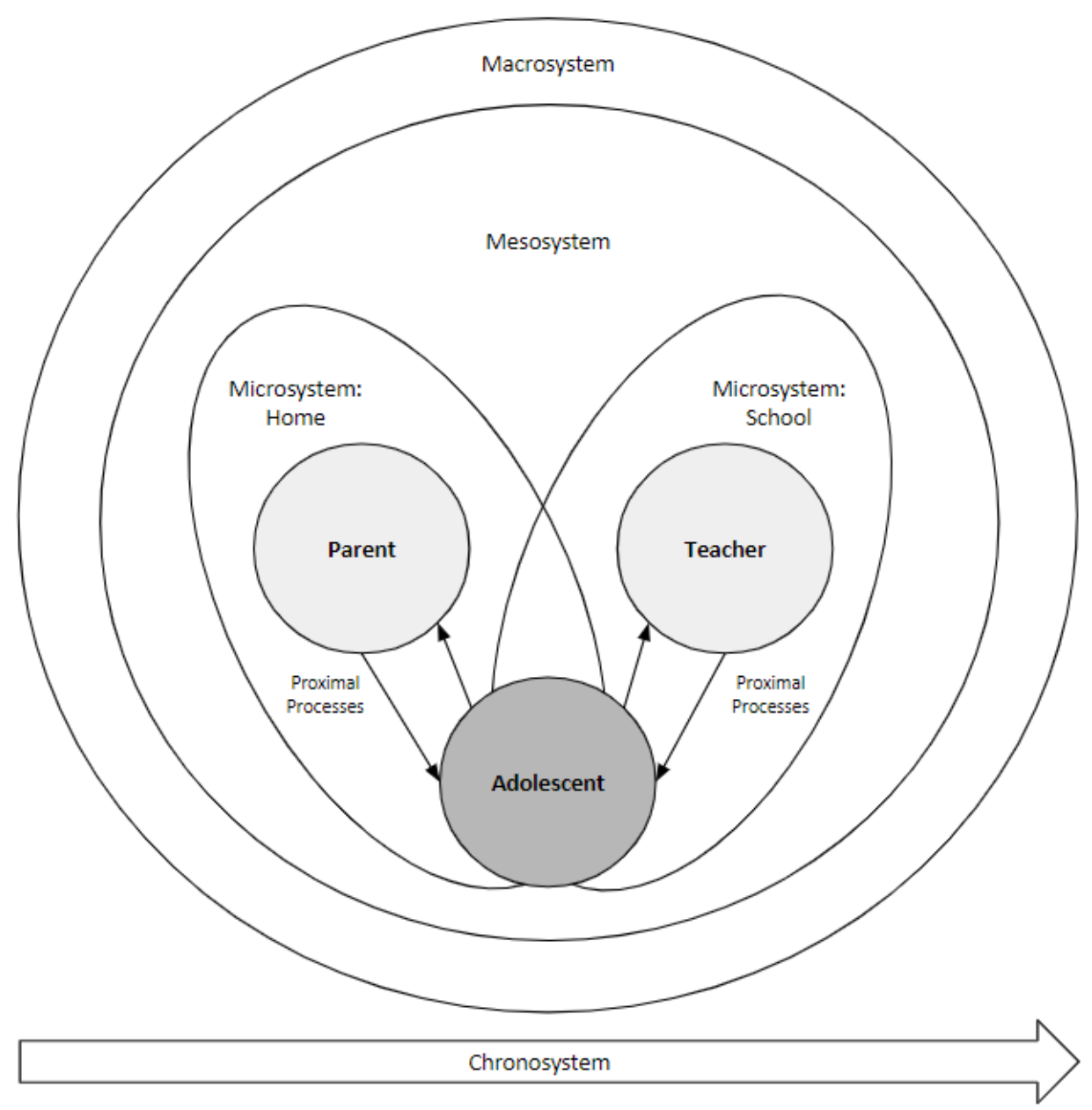

Figure 2.1. Bioecological model of adolescent development inspired by Bronfenbrenner $\&$ Morris (1998). 
Only a few researchers have begun to examine the combined influences of both parent and teacher involvement on adolescents' academic engagement in the same statistical model. Findings from these studies fall into two general categories: (1) cumulative effects, or the unique effects of each social partner working together where the effect of one cannot be replaced by the effects of the other, or (2) mediated effects, wherein the unique effects of one social partner are explained by a third variable. Table 2.1 summarizes the studies reviewed.

Cumulative effects. Three studies focused on adolescent academic engagement have found evidence for the cumulative effects of parent and teacher involvement and support. Using hierarchical regressions, Brewster and Bowen (2004) discovered that parent support (e.g., discussing selecting classes, activities at school, and encouraging students) as well as teacher support (e.g., students' perceptions of teachers caring, listening, and encouraging them) both positively and uniquely predicted Latino $6^{\text {th }}$ through $12^{\text {th }}$ grade students' sense of school meaningfulness, or perceptions that school is fun and exciting and looking forward to school. Similarly, Murray (2009) found that positive parental involvement (e.g., students' perceptions of parents liking to talk to them about school, knowing how well they can do in school, and helping them) and teacher closeness-trust (e.g., students' perceptions of their teachers as fair and feeling good when with their teachers) each positively and uniquely predicted Latino $6^{\text {th }}$ through $8^{\text {th }}$ grade students' behavioral engagement. In a third study, Quin, Hemphill, and Heerd (2017) found that both parent support of education (e.g., frequency of discussions with parents about school, grades, and teachers) and teacher relatedness support (e.g., perceptions of 
teachers caring about the student) positively and uniquely predicted year 7 Australian students' emotional engagement, but not their behavioral or cognitive engagement.

These three studies on adolescents' academic engagement are consistent with three other studies examining the combined effects of parents and teachers on other motivational outcomes. For example, Chouinard, Karsenti, and Roy (2007) found that parent and teacher support (i.e., perceived support and confidence expressed in their ability to succeed) positively and uniquely predicted twelve to eighteen-year-old students' competence beliefs, mastery achievement goals, and utility value for their math classes. Using latent growth models, You, Hong, and Ho (2011) found that for students followed from $8^{\text {th }}$ to $12^{\text {th }}$ grade, parent (e.g., discuss school activities, programs, and things studied) and teacher support (e.g., perceived interest in student, praise, and listening) each positively and uniquely predicted perceived control across ethnicities (Asian American, African American, Hispanic, and Caucasian), with teacher support having a stronger effect for African American students and parent support a stronger effect for Caucasian students. Further, Chan et al. (2013) found that the quality of both parent-child (i.e., trust and communication) and teacher-student (i.e., getting along, care what teacher thinks) relationships were positively and uniquely related to $4^{\text {th }}$ through $9^{\text {th }}$ grade students' positive self-esteem and academic attitudes over time, while controlling for the effects of mentor relationships from the Big Brothers and Big Sisters Program. The collective findings from these studies suggest that despite differences in the kind of involvement given by parents and teachers (e.g., parent support of education versus teacher relatedness support), together, each exert unique and positive influences on 
adolescents' academic engagement. These findings support the notion of cumulative effects of parents and teachers, in which both are important and the effects of one cannot be replaced by the other.

Mediated effects. Two additional studies of adolescents' engagement in school have found mediated effects for parent and teacher involvement. Duchesne and Larose (2007) found that teacher support (e.g., perceptions of math and French teachers' interest in students and consideration for their feelings) mediated the positive relation between parent-adolescent attachment quality (e.g., mutual trust, quality of communication) and $7^{\text {th }}$ grade students' academic motivation. Perry, Liu, and Pabian (2010) discovered that although teacher support (e.g., perceptions of teachers' interest in students' futures, high expectations, ease of communication) and parent career support (e.g., expressions of interest in adolescent issues, offering materials for careers) were both positively correlated with students' school engagement, parental career support only indirectly predicted students' school engagement through students' career preparation (e.g., career planning and career decision self-efficacy), while teacher support was positively and directly related. Findings from these two studies would suggest that the potentially more distal effects (i.e., in the home microsystem) of certain parent supports are not direct, but can be explained by the more proximal effects (i.e., in the classroom microsystem where engagement with academic tasks most often occurs) of teacher supports or other student processes. 
Table 2.1

Reviewed Studies of Combined Effects of Parent and Teacher Involvement

\begin{tabular}{|c|c|c|c|c|c|c|}
\hline Study & Sample Description & Design & $\begin{array}{l}\text { Parent } \\
\text { Variables }\end{array}$ & $\begin{array}{l}\text { Teacher } \\
\text { Variables }\end{array}$ & Outcome(s) & Findings \\
\hline \multicolumn{7}{|c|}{ Variable-Centered Studies } \\
\hline $\begin{array}{l}\text { Brewster \& } \\
\text { Bowen (2004) }\end{array}$ & $\begin{array}{l}6^{\text {th }}-12^{\text {th }} \text { grades } \\
\text { U.S. Latino } \\
\text { students, at risk for } \\
\text { school failure } \\
\mathrm{N}=633\end{array}$ & Cross-sectional & Support (SR) & Support (SR) & $\begin{array}{l}\text { School meaningfulness } \\
\text { (SR) }\end{array}$ & $\begin{array}{l}\mathrm{Pa}+\text { school } \\
\text { meaningfulness } \\
\mathrm{T}+\text { school } \\
\text { meaningfulness }\end{array}$ \\
\hline $\begin{array}{l}\text { Chan et al. } \\
\text { (2013) }\end{array}$ & $\begin{array}{l}4^{\text {th_-9th }} \text { grades } \\
\text { Part of intervention } \\
\text { study of } \\
\text { mentorships with } \\
\text { Big Brothers Big } \\
\text { Sisters } \\
\mathrm{N}=526\end{array}$ & Longitudinal & $\begin{array}{l}\text { Quality of } \\
\text { parent-child } \\
\text { relationship } \\
\text { (SR) }\end{array}$ & $\begin{array}{l}\text { Quality of } \\
\text { teacher-student } \\
\text { relationships } \\
\text { (SR) }\end{array}$ & $\begin{array}{l}\text { Academic attitudes (SR), } \\
\text { self-esteem (SR) }\end{array}$ & $\begin{array}{l}\mathrm{Pa}+\mathrm{T}+\text { academic } \\
\text { attitudes, self- } \\
\text { esteem }\end{array}$ \\
\hline $\begin{array}{l}\text { Chouinard, } \\
\text { Karsenti, \& } \\
\text { Roy (2007) }\end{array}$ & $\begin{array}{l}12-18 \text { yo } \\
(\mathrm{M}=15.08) \\
\text { Canada } \\
\mathrm{N}=759\end{array}$ & Cross-sectional & Support (SR) & $\begin{array}{l}\text { Support from } \\
\text { math teacher } \\
\text { (SR) }\end{array}$ & $\begin{array}{l}\text { Competence (SR), utility } \\
\text { value (SR), mastery goals } \\
\text { (SR) in math class }\end{array}$ & $\begin{array}{l}\mathrm{Pa}+\mathrm{T}+ \\
\text { competence, utility } \\
\text { value, mastery goals }\end{array}$ \\
\hline $\begin{array}{l}\text { Duchesne \& } \\
\text { Larose (2007) }\end{array}$ & $\begin{array}{l}7^{\text {th }} \text { grade }(M=12.97) \\
\text { Canada } \\
N=121\end{array}$ & Cross-sectional & $\begin{array}{l}\text { Parent- } \\
\text { adolescent } \\
\text { attachment } \\
\text { quality (SR) }\end{array}$ & Support (SR) & $\begin{array}{l}\text { Academic motivation } \\
\text { (SR) }\end{array}$ & $\begin{array}{l}\mathrm{Pa}+\mathrm{T}+\text { academic } \\
\text { engagement }\end{array}$ \\
\hline $\begin{array}{l}\text { Murray } \\
(2009)\end{array}$ & $\begin{array}{l}6^{\text {th }}-8^{\text {th }} \text { grades } \\
\text { U.S. Latino, lower } \\
\text { SES students } \\
N=104\end{array}$ & Cross-sectional & $\begin{array}{l}\text { Closeness-trust } \\
\text { and positive } \\
\text { involvement } \\
\text { (SR) }\end{array}$ & $\begin{array}{l}\text { Closeness-trust } \\
\text { and positive } \\
\text { involvement } \\
\text { (SR) }\end{array}$ & Engagement (SR) & $\begin{array}{l}\text { Pa pos involvement } \\
\text { + engagement } \\
\mathrm{T} \text { closeness-trust + } \\
\text { engagement }\end{array}$ \\
\hline $\begin{array}{l}\text { Perry, Liu, \& } \\
\text { Pabian (2010) }\end{array}$ & $\begin{array}{l}7^{\text {th }}-12^{\text {th }} \text { grade } \\
(\mathrm{M}=15.38) \\
\text { U.S. racially diverse } \\
\text { sample } \\
\mathrm{N}=285\end{array}$ & Cross-sectional & $\begin{array}{l}\text { Career support } \\
\text { (SR) }\end{array}$ & Support (SR) & School engagement (SR) & $\begin{array}{l}\mathrm{T}+\text { school } \\
\text { engagement }\end{array}$ \\
\hline $\begin{array}{l}\text { Quin, } \\
\text { Hemphill, \& } \\
\text { Heerde (2017) }\end{array}$ & $\begin{array}{l}\mathrm{M}=12.8 \\
\text { Australia } \\
\mathrm{N}=88\end{array}$ & Cross-sectional & $\begin{array}{l}\text { Support of } \\
\text { education (SR) }\end{array}$ & $\begin{array}{l}\text { Relatedness } \\
\text { support (SR) }\end{array}$ & $\begin{array}{l}\text { Behavioral engagement } \\
\text { (SR), cognitive } \\
\text { engagement (SR), } \\
\text { emotional engagement } \\
\text { (SR) }\end{array}$ & $\begin{array}{l}\mathrm{Pa}+\text { emotional } \\
\text { engagement } \\
\mathrm{T}+\text { emotional } \\
\text { engagement }\end{array}$ \\
\hline $\begin{array}{l}\text { You, Hong, \& } \\
\text { Ho (2011) }\end{array}$ & $\begin{array}{l}8^{\text {th }} \text { grade } \\
\text { U.S. racially diverse } \\
\text { sample } \\
\mathrm{N}=6000\end{array}$ & Longitudinal & Support (SR) & Support (SR) & $\begin{array}{l}\text { Perceived control (SR), } \\
\text { behavioral engagement } \\
\text { (SR) }\end{array}$ & $\begin{array}{l}\mathrm{Pa}+\mathrm{T}+\text { perceived } \\
\text { control }\end{array}$ \\
\hline
\end{tabular}

Note. $\mathrm{SR}=$ Student Report $\mathrm{Pa}=$ Parent $; \mathrm{T}=$ Teacher

Importance and limitations of combined effects studies. By examining both

adult social partners simultaneously in their analyses, these studies are an important progression in research on the combined effects of parent and teacher involvement on adolescents' academic engagement. Modeling the combined effects of parents and teachers not only allows for a more realistic representation of adolescents' social 
ecologies in which they interact with both parents and teachers on a daily basis, but it also allows for a more sophisticated examination of their cumulative and mediated effects.

While these studies are an improvement over studies that examine the effects of parents and teachers individually, they are still limited in several ways. First, six of these eight studies were cross-sectional, restricting their ability to examine changes in the nature and effects of parent and teacher involvement on adolescents' academic engagement. As such, it is impossible to answer the questions: Do parent and teacher involvement predict later adolescent academic engagement? Does the nature of these effects change over time, becoming stronger or weaker? In order to better answer these questions, future studies should examine these issues longitudinally. Second, only one of the eight studies tested for interaction effects between parent and teacher support (Murray, 2009). Although these studies are focused on the combined effects of parents and teachers, strictly examining their unique effects limits an understanding of their dynamic, joint influence. The one study that did test for an interaction (i.e., parent positive involvement $\mathrm{x}$ teacher closeness-trust) failed to find a statistically significant effect. This could mean that parent and teacher effects are not contextualized. Or, it could be due to methodological reasons such as high levels of multicollinearity between variables assessing each social partner and the interaction term. This is a common issue when using single-report constructs (i.e., all student report measures), which all of these studies used. 
Finally, all eight of these studies are restricted in their focus on the unidirectional effects of parents and teachers on adolescents. Perhaps in part because of their crosssectional nature, these studies simply posited that parent and teacher involvement predict adolescent academic engagement, with no reciprocal, bidirectional, or feedback effects considered. As active, agentic individuals who interact with and affect their environments, adolescents may (and studies find that they do in fact as discussed in the next section) exert dynamic influences on their adult social partners. To address this limitation, future studies should include the bidirectional influence of adolescents on the continued involvement of their parents and teachers.

\section{Reciprocal Effects of Adolescent Engagement}

Although the proximal processes occurring between adolescents and their adult social partners are theorized to be bidirectional in nature (Bronfenbrenner \& Morris, 1998), these effects have typically been examined unidirectionally. As adolescents are emotionally, behaviorally, and cognitively engaged with their academic work, their actions can reciprocally influence their adult social partners, reinforcing and sustaining their involvement and support. In contrast, when students are disaffected and disengaged from school and academics, as often occurs during the transition to middle school, these reciprocal effects may result in the withdrawal of parent and teacher involvement (Connell \& Wellborn, 1991; Skinner \& Pitzer, 2012). The few studies that have examined these reciprocal or feedback effects have found some supportive evidence either in experimental studies, wherein children are coached on how to act and parent responses are recorded, or in longitudinal studies where temporal precedence is established. 
In a study of German students and their parents, it was found that students' engagement and achievement in $5^{\text {th }}$ grade predicted their parents' behavior two years later when students were in $7^{\text {th }}$ grade: (1) when $5^{\text {th }}$ graders exerted reading effort, their parents' homework involvement in $7^{\text {th }}$ grade was characterized as controlling but with the provision of structure; (2) when the children procrastinated on their homework in $5^{\text {th }}$ grade, their parents were less responsive in $7^{\text {th }}$ grade; (3) however, when the children had higher reading achievement, their parents were less controlling in $7^{\text {th }}$ grade (Dumont, Trautwein, Nagy, \& Nagengast, 2014). This study supports the idea that parents respond to their students' academic engagement or disaffection with either continued involvement or the withdrawal of their support. In a longitudinal study, Skinner and Belmont (1993) discovered that in response to $3^{\text {rd }}-5^{\text {th }}$ grade students' behavioral engagement in the fall, teachers became more involved, autonomy supportive, and provided more structure over the school year. In contrast, when students initially were more behaviorally disaffected, teachers tended to respond by becoming more neglectful, coercive, or lacking structure. When the $3^{\text {rd }}-5^{\text {th }}$ graders were emotionally engaged, their teachers became more involved and autonomy supportive. When students were emotionally disaffected in the fall, teachers compensated by being more autonomy supportive across the school year. This work suggests that depending on how students act in the classroom (i.e., engaged or disaffected), teachers respond either with their continued involvement or the withdrawal of resources.

In addition to these two longitudinal studies, some cross-sectional studies have claimed to find the existence of reciprocal effects of adolescents on their adult social 
partners. Connell, Spencer, and Aber (1994) found in a path model testing the self-system processes model of motivation that African American early adolescents' emotional and behavioral engagement was significantly related to increases in their parents' involvement and dedication of psychological resources. Further, a meta-analysis by Nurmi (2012) found in seven cross-sectional studies that as students were engaged and motivated at school and in the classroom, teachers reported closer teacher-student interactions with less conflict. Although these studies have interpreted these concurrent correlations as evidence for the reciprocal effects of adolescents, they cannot be considered definitive evidence for feedback or feedforward effects due to their crosssectional design. Therefore, while reciprocal effects may be a prevalent idea in the literature, more rigorous longitudinal or experimental research is necessary to conclusively test their existence.

\section{Summary}

Adolescent academic engagement has been a concern to parents, teachers, and researchers because it shows normative declines across the transition to middle school, resulting from a mismatch between students' developmental needs and the affordances found in middle schools. While research has found that parent and teacher warm involvement are each supportive of adolescents' academic engagement, few studies have examined their effects simultaneously as multiple social ecologies that adolescents experience every day, or longitudinally across the school year and the transition to middle school. No studies examining the combined influence of parent and teacher warm involvement have examined the active, reciprocal influence of adolescents on their adult 
social partners. In order to offer a holistic understanding of adolescents' complex social ecologies, it is important for research to study the combined, dynamic influence of parent and teacher warm involvement on adolescents' academic engagement, changes in the nature of these effects and social ecologies, and the reciprocal influence of adolescents on the continued involvement of their adult social partners. Two studies were designed to address these issues and will be discussed in the following sections. 


\section{Chapter 3: Study 1}

Parent and Teacher Involvement and Adolescent Academic Engagement:

Combined and Reciprocal Effects across the Transition to Middle School

The transition to middle school is often a challenging time for adolescents, as can be seen by the normative declines typically found in their academic engagement and motivation (Wigfield et al., 2015). To negotiate this transition, students rely on support from trusted adults. Decades of research have demonstrated that parent and teacher involvement can have a positive impact on adolescents' academic motivation as they enter middle school. Parents and teachers each function as key social partners, important adult figures, and meaningful role models in adolescents' academic lives. Yet, just as adolescents need relationships more, some evidence indicates that the quality of their connections with parents and teachers may be declining. As adolescents seek more independence from their parents, they reach out to other adults such as teachers. However, middle school teachers, who are teaching multiple classes with higher enrollments, find it more and more difficult to develop warm, supportive relationships with their students (Eccles \& Roeser, 2015). Together, these changes in the nature of relationships with adult social partners have the potential to leave adolescents without the academic support and involvement that they need to promote their engagement in school during this challenging time.

Although research has found that parent and teacher warm involvement each individually benefit students' academic motivation, the effects of parents and teachers 
have typically been examined through separate lines of research focusing on only a single social partner. To gain a fuller picture of adolescents' academic lives and how best to promote their engagement, it is important for research to examine the combined effects of both social partners. One way to highlight these combined, dynamic relations is through the process model shown in Figure 3.1. This model posits that supports from the social context (i.e., parent or teacher involvement) shape and influence adolescent functioning (i.e., adolescent engagement), while at the same time, adolescent functioning also shapes the kinds of social supports they will subsequently receive. This framework tries to capture the dynamic, reciprocal interactions of social partners working together over time. The current study draws upon this path model to conceptualize and explore the reciprocal relations between parent and teacher involvement and adolescents' academic engagement, and examines these influences as they unfold longitudinally across the school year.

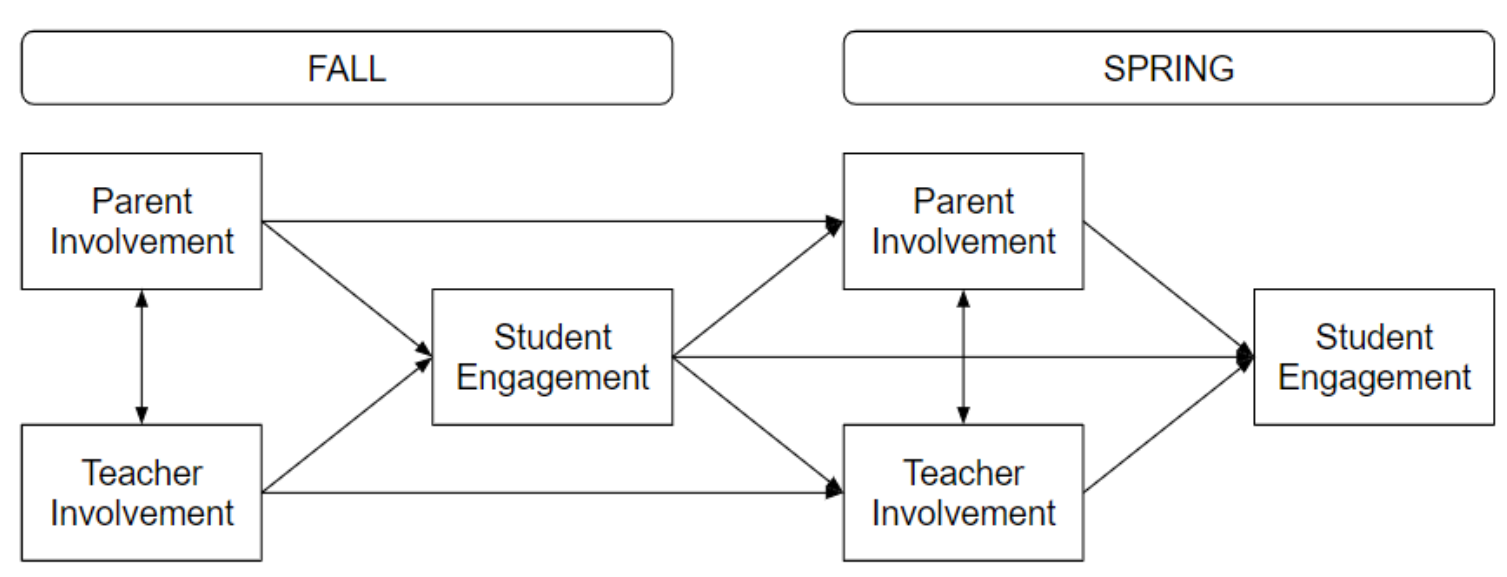

Figure 3.1. Proposed path model of the combined, dynamic effects of parent and teacher involvement and the reciprocal effects of adolescent academic engagement. 


\section{Individual Effects of Parent and Teacher Involvement on Student Engagement}

Involvement from parents and teachers, characterized by warm, supportive relationships, is crucial during the adolescent years in order to support students' engagement with academic work. The need for relatedness and the role of interpersonal relationships is a common theme in many theories of achievement motivation (see Martin \& Dowson, 2009). Specifically, research has suggested that secure, interpersonal relationships can help foster students' curiosity, exploration, and positive coping skills (Wentzel, 2016). While these secure relationships have generally been studied with parents or caregivers, Wentzel (2016) argues that similar positive benefits should accrue within teacher-student relationships as well, with initial evidence supporting this contention. Separate lines of research provide evidence for the positive effects of parents and of teachers on adolescents' academic engagement and motivation.

Parent involvement and student engagement. Decades of research have found that parent involvement is positively related to adolescents' academic motivation and engagement (Bempechat \& Shernoff, 2012; Raftery, Grolnick, \& Flamm, 2012). For example, parental behavioral involvement (i.e., attending school functions, parent-teacher conferences, etc.) and cognitive involvement (i.e., exposing students to books, current events, etc.) are each associated with increases in students' academic competence and grades (Grolnick, Friendly, \& Bellas, 2009). In a review of empirical research examining the development of school engagement in different social contexts, Upadyaya and Salmela-Aro (2013) concluded, “....several family characteristics, such as parental involvement, affection, monitoring, and support, positively predict students' engagement 
with school at all grade levels" (p. 141). The studies they reviewed found that students who have high quality relationships with their parents and whose parents are involved, mastery-oriented, and authoritative tend to be more academically engaged and more likely to graduate from high school.

Teacher involvement and student engagement. A wealth of research on teachers has found that close, emotionally supportive relationships between students and teachers are associated with middle school students' perceived control, autonomy, and self-esteem (Wentzel, 2016; Wigfield et al., 2015), and adolescents' academic motivation and engagement (Pianta, Hamre, \& Allen, 2012). Upadyaya and Salmela-Aro (2013) also found that close teacher-student relationships, teacher support, and teacher modeling of engagement are crucial for fostering adolescents' own engagement. Several metaanalyses have also found that positive teacher-student relationships contribute to higher levels of adolescents' engagement in school (Quin, 2017; Roorda, Koomen, Spilt, \& Oort, 2011).

\section{Combined Effects of Parent and Teacher Involvement}

While separate lines of research demonstrate the importance of each social partner in supporting adolescents, to date, only five studies have examined the joint effects of both parent and teacher involvement on students' engagement during middle school. Their findings support the premise that close relationships with each social partner are uniquely important to students' academic engagement, but results suggest two kinds of combined effects: cumulative effects, in which the influences of both parents and teachers work in tandem with each other and neither can be replaced by the other social 
partner, and mediated effects, wherein the influences of one are exerted through their impact on the other or on a characteristic of students.

Cumulative effects of parents and teachers. Three studies found that parent and teacher involvement were each positively and uniquely related to adolescents' academic engagement. For example, in a series of hierarchical regressions, Quin, Hemphill, and Heerd (2017) found that parent support for education and teacher support for relatedness were each positively and uniquely related to year 7 Australian students' emotional engagement. In another set of hierarchical regressions, Murray (2009) found that parents' positive involvement and teacher closeness-trust each positively and uniquely predicted student engagement in a sample of $6^{\text {th }}, 7^{\text {th }}$, and $8^{\text {th }}$ grade predominately Latino students. Similarly, Brewster and Bowen (2004) found that parent support (i.e., discussing selecting courses, activities at school, things learned in class, etc.) and teacher support (i.e., perceptions of teachers caring, listening, encouraging students, etc.) each positively and uniquely predicted Latino middle and high school students' school meaningfulness (i.e., perceiving school as fun and exciting, looking forward to school).

Mediated effects of parents and teachers. In contrast to cumulative effects, two of the reviewed studies found evidence for mediated effects of parent or teacher involvement on adolescents' academic engagement. For example, Duchesne and Larose (2007) discovered that the effects of parent attachment quality on grade 7 adolescents' academic motivation was mediated via its impact on teacher support. By the same token, Perry, Liu, and Pabian (2010) found that while teacher support and parental career support each had positive zero-order correlations with students' school engagement, only 
teacher support positively and directly predicted students' school engagement in a structural equation model. Parental career support predicted students' school engagement only indirectly through students' own career preparation.

By examining both social partners within the same statistical model, these studies have demonstrated that students' academic engagement depends on support from both parents and teachers, and that each make contributions that the other does not. The discovery of both cumulative and mediated effects suggests the importance of examining the combined effects of both social partners within the same model in order to more fully understand their collective influences. At the same time, these studies are not without certain limitations. Like research on the individual effects of parents and teachers, all of these studies were solely cross-sectional in nature. As such, they were unable to examine causal precedence, the changing dynamics in the effects of parents and teachers on adolescents' academic engagement, or the reciprocal influences of adolescents on their adult social partners.

\section{Reciprocal Effects of Student Engagement}

Although previous studies examining the combined effects of parents and teachers are an improvement over research examining them separately, they still lack the complete, dynamic picture suggested by our hypothesized path model. Specifically, they do not consider the reciprocal effects of adolescents on their adult social partners. As students act in ways demonstrating their behavioral and emotional engagement with academic work, these actions can feed into and reinforce the continued involvement and support of parents and teachers, thus creating a virtuous cycle of involvement and 
engagement (Connell \& Wellborn, 1991; Skinner \& Pitzer, 2012). Or as adolescents disengage from school work, become bored or disaffected in the classroom, and give up in the face of challenges, parents and teachers may respond to these actions by withdrawing their academic support and warm involvement, creating a vicious cycle. Although they are rare, the few longitudinal studies examining students' impact on their parents and teachers suggest that such reciprocal effects are possible.

For example, in a sample of students from different school tracks in Germany, Dumont, Trautwein, Nagy, \& Nagengast (2014) found that when children exerted more reading effort in $5^{\text {th }}$ grade, their parents were more controlling and provided more structure in their homework involvement in $7^{\text {th }}$ grade. However, when children procrastinated more on their homework in $5^{\text {th }}$ grade, parents were less responsive; when children had higher reading achievement in $5^{\text {th }}$ grade, parents were less controlling. In addition, Skinner and Belmont (1993) found that when $3^{\text {rd }}-5^{\text {th }}$ grade students were initially more behaviorally engaged, teachers provided increasing levels of involvement, autonomy support, and structure as the year progressed. On the other hand, when students were passive or withdrawn at the beginning of the school year, teachers were more likely to behave in ways that were neglectful, coercive, or lacked consistency and contingency as the year progressed. Students' emotional engagement also predicted increases in teacher involvement and autonomy support such that for students who were initially more interested, curious, and enthusiastic, teachers were increasingly more attentive and allowed more opportunities for choice and freedom. Further, teachers attempted to compensate for students' low emotional engagement in the fall by subsequently 
providing more autonomy support in the face of those students' anxiety and boredom in the classroom. Given support for the reciprocal effects of students on parents and teachers as examined separately in previous research, the current study sought to explore not only the combined effects of parent and teacher involvement on adolescents' academic engagement but also the reciprocal effects of adolescent engagement on changes in parents' and teachers' involvement across the school year.

\section{Current Study}

Using longitudinal data from two time points (fall and spring of the same school year) from a cross-section of $5^{\text {th }}, 6^{\text {th }}$, and $7^{\text {th }}$ grade students, two research questions guided this study's examination of the combined effects of parent and teacher involvement on the development of adolescents' academic engagement:

1. Combined effects. Do parent and teacher involvement each uniquely predict adolescents' academic engagement across the school year?

2. Reciprocal effects. Does adolescent academic engagement reciprocally predict both parent and teacher involvement across the school year?

We hypothesized that both parent and teacher involvement would each positively and uniquely predict adolescents' academic engagement (RQ1), controlling for the other social partner's involvement, suggesting cumulative effects. We also anticipated that adolescent academic engagement would positively predict both parents' and teachers' subsequent involvement (RQ2). Taken together, the feedforward effects of adult support and feedback effects of student engagement would suggest a "rich get richer" pattern of change over time: Students whose parents and teachers are supportive would show 
higher subsequent levels of engagement, which in turn would lead to more support from adults. In contrast, students who experience their parents and teachers as unsupportive would potentially become more disaffected, which in turn might lead parents and teachers to further withdraw their support.

\section{Method}

\section{Participants}

Data for this study come from an existing longitudinal dataset that evaluated an entire rural-suburban school district in upstate New York. Participants in the current study included 371 students in $5^{\text {th }}$ grade, ages 9 to 12 years old $(M=10.30) ; 377$ students in $6^{\text {th }}$ grade, ages 10 to $14(M=11.33)$; and 342 students in $7^{\text {th }}$ grade, ages 12 to $14(M=$ 12.34). Half of the participants were female (52.7\%) and almost all were White (95\%).

\section{Design and Procedure}

This cross-section of $5^{\text {th }}$ to $7^{\text {th }}$ graders was followed over two time points during a single school year. Students completed assent forms before completing surveys administered by trained interviewers across three 40-minute class sessions in October (fall) and May (spring) of the same school year. One interviewer read the questions out loud to students while the other walked around the room answering students' questions. Teachers were not present during student data collection, and students were assured that their responses would remain confidential and not influence their standing in the class at all.

\section{Measures}


For all measures used in the current study, students rated items on a 4-point scale $(1=$ not at all true for me, $2=$ not very true for me, $3=$ sort of true for me, $4=$ very true for me). Items on each scale were averaged (with negative items reverse-coded) so that all scales ranged from 1-4, with higher ratings indicating more of the respective construct.

Perceived parent warm involvement. Students rated the quality of their parents' warm affection, caring, and attention using five items (Skinner, Johnson, \& Snyder, 2005; e.g., "My parents know a lot about what's important to me," "When I want to talk, my parents take the time to listen," and "Sometimes I think my parents don't care about what goes on for me," reverse-coded). Reliabilities were adequate at each time point across all grades $\left(\alpha_{\mathrm{F} 5}=.81, \alpha_{\mathrm{S} 5}=.80, \alpha_{\mathrm{F} 6}=.78, \alpha_{\mathrm{S} 6}=.70, \alpha_{\mathrm{F} 7}=.75, \alpha_{\mathrm{S} 7}=.79\right)$.

Perceived teacher warm involvement. Students also rated their teachers' pedagogical caring using five items (Skinner \& Belmont, 1993; $\alpha_{\mathrm{F} 5}=.86, \alpha_{\mathrm{S} 5}=.84, \alpha_{\mathrm{F} 6}=$ $\left..80, \alpha_{\mathrm{S} 6}=.74, \alpha_{\mathrm{F} 7}=.79, \alpha_{\mathrm{S} 7}=.80\right)$. Example items included "My teacher likes me," "My teacher really cares about me," and "My teacher just doesn't understand me” (reversecoded).

Adolescent academic engagement. Students rated their levels of behavioral and emotional engagement and disaffection (reverse-coded) across fall and spring.

Behavioral engagement. Students reported on six items tapping their effort and active behavioral participation in learning activities (Skinner, Kindermann, \& Furrer, $\left.2009 ; \alpha_{\mathrm{F} 5}=.78, \alpha_{\mathrm{S} 5}=.74, \alpha_{\mathrm{F} 6}=.75, \alpha_{\mathrm{S} 6}=.70, \alpha_{\mathrm{F} 7}=.74, \alpha_{\mathrm{S} 7}=.67\right)$. Example items 
included "I try very hard in school," "I participate in class discussions," and "When we start something new, I practically fall asleep" (reverse-coded).

Emotional engagement. Students rated nine items tapping their positive and negative emotions while participating in learning activities in the classroom (Skinner et al., 2009; $\left.\alpha_{\mathrm{F} 5}=.86, \alpha_{\mathrm{S} 5}=.87, \alpha_{\mathrm{F} 6}=.79, \alpha_{\mathrm{S} 6}=.82, \alpha_{\mathrm{F} 7}=.82, \alpha_{\mathrm{S} 7}=.85\right)$, such as "When we start something new in class, I feel interested," "When I'm doing my work in class, I feel worried" (reverse-coded), and "When I'm in class, I feel happy."

\section{Results}

\section{Missing Data}

Missing data patterns were examined along with Little's missing completely at random (MCAR) test (Little, 1988). In $5^{\text {th }}$ grade, missing data ranged from $43.7 \%$ to 52.6\% across all measures (Fall: $43.7 \%-47.2 \%$, Spring: $46.6 \%-52.6 \%$ ). In $6^{\text {th }}$ grade, missing data ranged from $17.8 \%$ to $27.1 \%$ across all measures (Fall: $17.8 \%-21.5 \%$, Spring: $22.0 \%-27.1 \%)$. In $7^{\text {th }}$ grade, missing data ranged from $17.3 \%$ to $54.7 \%$ across all measures (Fall: $17.3 \%-22.8 \%$, Spring: 49.4\%-54.7\%). Little's MCAR test was significant for the sample of $5^{\text {th }} \operatorname{graders}\left(\chi^{2}(3683)=4260.01, p<.001\right), 6^{\text {th }}$ graders

$\left(\chi^{2}(4265)=4569.74, p<.001\right)$, and $7^{\text {th }}$ graders $\left(\chi^{2}(2827)=3081.13, p<.001\right)$, suggesting that data was not missing completely at random. Across variables, students with data present tended to have higher means than students missing all other variables; therefore, missing data was addressed using full information maximum likelihood estimation in order to represent the range of student experiences.

\section{Descriptive Analyses}


Prior to examining the main research questions, descriptive analyses, including means, standard deviations, and correlations, were calculated for all variables at each time point across grades (see Table 3.1). As expected, student reports of parent involvement, teacher involvement, and their own behavioral and emotional engagement were positively and significantly related to one another at all time points for students from all three grades, and cross-year stabilities were relatively high (averaging .67). As is typical, involvement from both social partners and both aspects of engagement showed declines across the school year and evinced lower mean levels at successive grades.

\section{Path Models}

In order to examine research questions focused on the combined effects of parent and teacher involvement and the reciprocal effects of adolescents' academic engagement for $5^{\text {th }}, 6^{\text {th }}$, and $7^{\text {th }}$ grade students, structural equation modeling (SEM) was used to analyze two path models each for behavioral and emotional engagement separately. First, the hypothesized model in Figure 3.1 was examined wherein all effects between the grades were constrained to be equal. Second, a model in which adolescents' engagement was the foremost predictor of parent and teacher involvement was examined, also with all effects across grades constrained to equal each other. This second model was analyzed in order to more clearly understand the possible feedback effects of adolescents on their social partners' warm support. Fit for all models was assessed by examining the $\chi^{2}$ goodness of fit test, comparative fit index (CFI), Tucker-Lewis index (TLI), standardized root mean squared residual (SRMR), root mean square error of approximation (RMSEA), and standardized correlation residuals. Following standard cutoff criteria guidelines (Hu 
$\&$ Bentler, 1999), CFI and TLI > .95 were considered good fit and $>.90$ adequate fit, and SRMR and RMSEA $<.06$ were considered good fit and $<.08$ adequate fit.

Table 3.1

Descriptives and Correlations among Variables for $5^{\text {th }}, 6^{\text {th }}$, and $7^{\text {th }}$ Grade Students

\begin{tabular}{|c|c|c|c|c|c|c|c|c|}
\hline Grade 5 & 1. & 2. & 3. & 4. & 5. & 6. & 7. & 8. \\
\hline 1. Parent Inv FA & -- & & & & & & & \\
\hline 2. Parent Inv SP & $.74 * * *$ & -- & & & & & & \\
\hline 3. Teacher Inv FA & $.44 * * *$ & $.37 * * *$ & -- & & & & & \\
\hline 4. Teacher Inv SP & $.30 * * *$ & $.36 * * *$ & $.51 * * *$ & - & & & & \\
\hline 5. BehEngage FA & $.41 * * *$ & $.45 * * *$ & $.53 * * *$ & $.49 * * *$ & -- & & & \\
\hline 6. BehEngage SP & $.36 * * *$ & $.46 * * *$ & $.37 * * *$ & $.57 * * *$ & $.70 * * *$ & -- & & \\
\hline 7. EmoEngage $\mathrm{FA}$ & $.53 * * *$ & $.63^{* * *}$ & $.58 * * *$ & $47^{* * *}$ & $.69 * * *$ & $.58 * * *$ & -- & \\
\hline 8. EmoEngage SP & $.45^{* * *}$ & $.58 * * *$ & $.49 * * *$ & $.65 * * *$ & $.56 * * *$ & $.68 * * *$ & $.72 * * *$ & -- \\
\hline$M(S D)$ & $3.49(.59)$ & $3.35(.66)$ & $3.33(.69)$ & $3.18(.72)$ & $3.29(.57)$ & $3.25(.56)$ & $3.29(.57)$ & $3.22(.57)$ \\
\hline Grade 6 & 1. & 2. & 3. & 4. & 5. & 6. & 7. & 8 \\
\hline 1. Parent Inv FA & -- & & & & & & & \\
\hline 2. Parent Inv SP & $.67 * * *$ & -- & & & & & & \\
\hline 3. Teacher Inv FA & $.36 * * *$ & $.31 * * *$ & -- & & & & & \\
\hline 4. Teacher Inv SP & $.33 * * *$ & $.45 * * *$ & $.67 * * *$ & -- & & & & \\
\hline 5. BehEngage FA & $.48 * * *$ & $49 * * *$ & $.46 * * *$ & $.36 * * *$ & -- & & & \\
\hline 6. BehEngage SP & $.40 * * *$ & $.48 * * *$ & $.40 * * *$ & $.50 * * *$ & $.64 * * *$ & -- & & \\
\hline 7. EmoEngage $\mathrm{FA}$ & $.44 * * *$ & $.38 * * *$ & $.52 * * *$ & $.38 * * *$ & $.56 * * *$ & $.45 * * *$ & -- & \\
\hline 8. EmoEngage SP & $.43^{* * *}$ & $.60 * * *$ & $.41^{* * *}$ & $.51 * * *$ & $.53 * * *$ & $.59 * * *$ & $.66^{* * *}$ & -- \\
\hline$M(S D)$ & $3.28(.63)$ & $3.18(.63)$ & $3.03(.67)$ & $2.88(.66)$ & $3.14(.55)$ & $3.04(.52)$ & $3.17(.53)$ & $3.05(.58)$ \\
\hline Grade 7 & 1. & 2. & 3. & 4. & 5. & 6. & 7. & 8. \\
\hline 1. Parent Inv FA & -- & & & & & & & \\
\hline 2. Parent Inv SP & $.75 * * *$ & -- & & & & & & \\
\hline 3. Teacher Inv FA & $.37 * * *$ & $.41 * * *$ & -- & & & & & \\
\hline 4. Teacher Inv SP & $.36 * * *$ & $.42 * * *$ & $.75 * * *$ & - & & & & \\
\hline 5. BehEngage FA & $.49 * * *$ & $.39 * * *$ & $.54 * * *$ & $.43 * * *$ & -- & & & \\
\hline 6. BehEngage SP & $49 * * *$ & $.51 * * *$ & $.39 * * *$ & $.43^{* * *}$ & $.55 * * *$ & -- & & \\
\hline 7. EmoEngage $\mathrm{FA}$ & $.46 * * *$ & $.46 * * *$ & $.52 * * *$ & $.57 * * *$ & $.61 * * *$ & $.42 * * *$ & -- & \\
\hline 8. EmoEngage SP & $.53 * * *$ & $.52^{* * *}$ & $.53 * * *$ & $.58^{* * * *}$ & $.54 * * *$ & $.58 * * *$ & $.72 * * *$ & -- \\
\hline$M(S D)$ & $3.18(.65)$ & $2.99(.71)$ & $2.88(.69)$ & $2.68(.74)$ & $3.02(.53)$ & $2.91(.48)$ & $3.06(.55)$ & $2.99(.58)$ \\
\hline
\end{tabular}

Note. Parent Inv $=$ Parent Involvement, Teacher Inv $=$ Teacher Involvement, BehEngage $=$ Student Behavioral Engagement, EmoEngage $=$ Student Emotional Engagement, FA $=$ Fall, SP = Spring. Shaded coefficients are cross-time stabilities from fall to spring. $* * * p<.001$

Behavioral engagement. As shown in Figures 3.2 and 3.3, both models for behavioral engagement demonstrated good fit and indicated that involvement from parents and teachers contributed positively to $5^{\text {th }}, 6^{\text {th }}$, or $7^{\text {th }}$ graders' behavioral 
engagement in fall and spring. In other words, parents' and teachers' warm support each made a unique contribution to adolescents' constructive on-task participation with academic work, over and above the supports provided by the other social partner. These effects were not significantly different across $5^{\text {th }}, 6^{\text {th }}$, and $7^{\text {th }}$ grade students. Similarly, in both models there was consistent support for the reciprocal effects of students' behavioral engagement on the subsequent involvement of their social partners. Students who were more behaviorally engaged with their academic work also reported that both their parents and teachers became more involved as the year progressed.

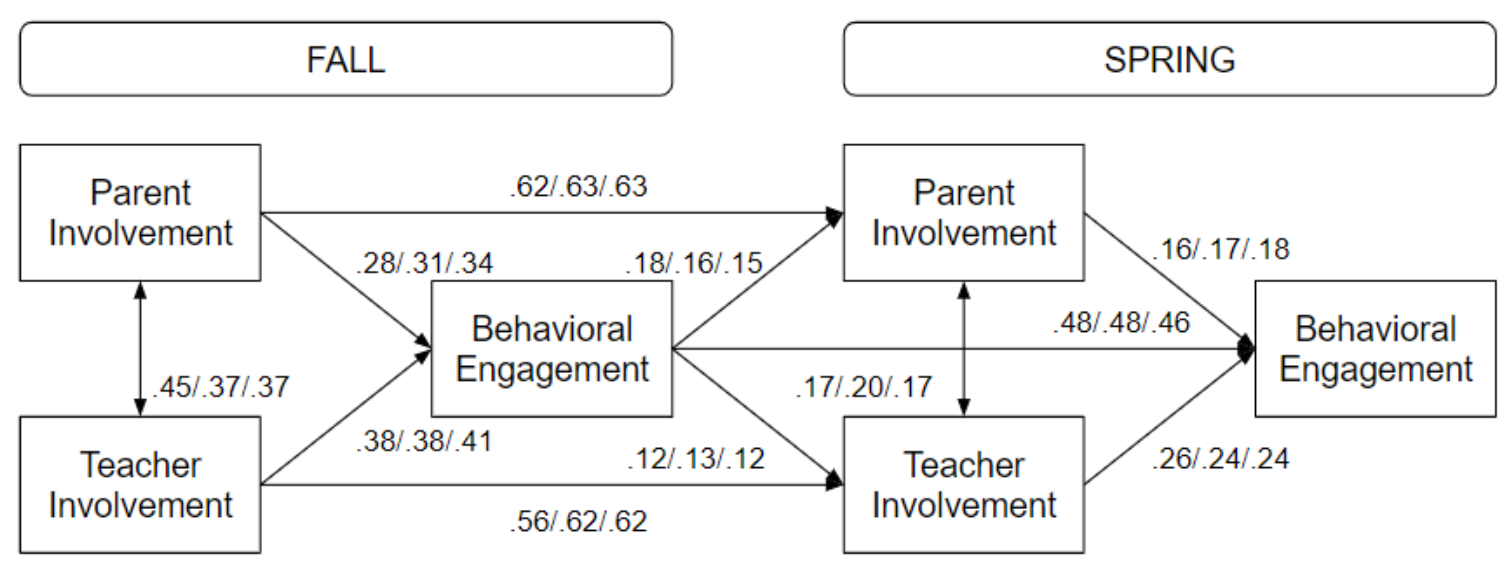

Figure 3.2. Constrained effects path model for behavioral engagement. $5^{\text {th }} / 6^{\text {th }} / 7^{\text {th }}$ grade effects. All effects were standardized, and unless otherwise noted, significant at least at $p$ $<.10 . \chi^{2}(30)=53.17 p<.01 ; \mathrm{CFI}=.98, \mathrm{TLI}=.98, \mathrm{RMSEA}=.05, \mathrm{SRMR}=.05 .92 .1 \%$ of standardized correlation residuals were less than $|2.00|$. 


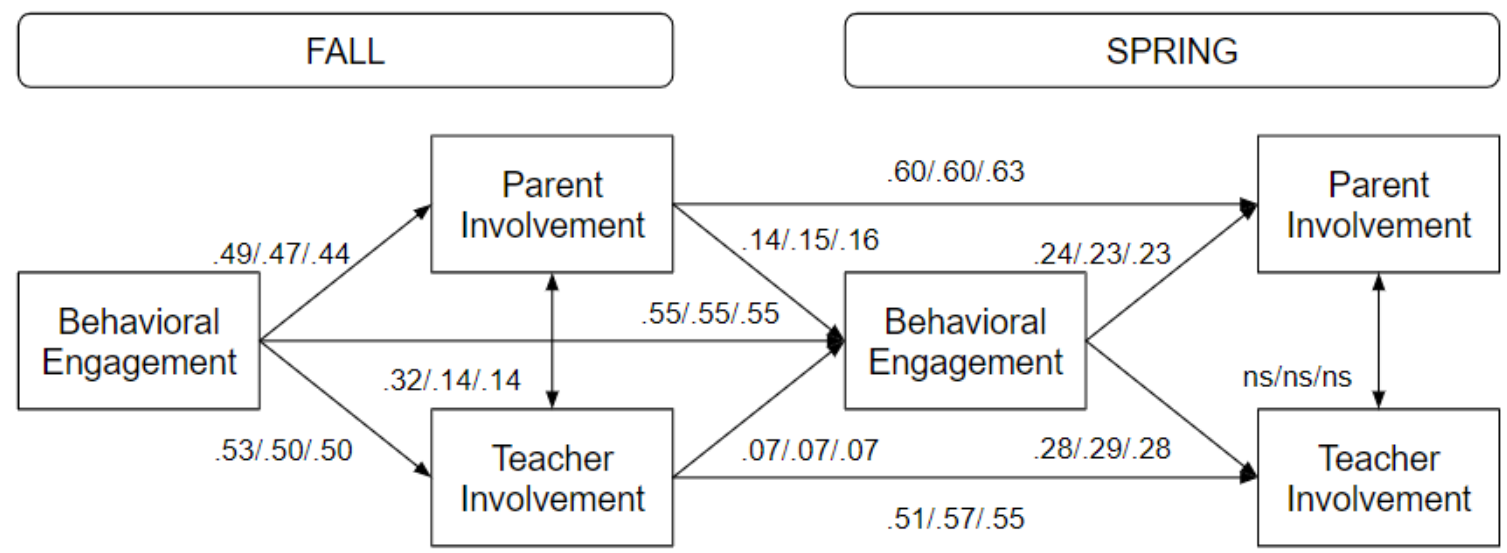

Figure 3.3. Constrained effects alternative path model for behavioral engagement. $5^{\text {th }} / 6^{\text {th }} / 7^{\text {th }}$ grade effects. All effects were standardized, and unless otherwise noted, significant at least at $p<.10 . \chi^{2}(30)=52.10 p<.01 ; \mathrm{CFI}=.98, \mathrm{TLI}=.98, \mathrm{RMSEA}=.06$, $\mathrm{SRMR}=.06 .88 .9 \%$ of standardized correlation residuals were less than $|2.00|$.

Although the pattern of significant effects was similar across both models, of note, the magnitude of effects differed depending on which social partner was modeled as the driving force of effects across the school year: adults or adolescents. When parents and teachers were modeled as the leading independent variables, their cumulative effects on adolescents' behavioral engagement were stronger than the reciprocal effects of adolescents. Yet, when adolescents were modeled as the leading independent variable, their feedforward effects on parents' and teachers' warm involvement were stronger than adults' feedback effects. In other words, as would be expected, concurrent effects were stronger than predictions of change over time, even though both were significant in both models.

Emotional engagement. Both models for emotional engagement demonstrated good fit as well (see Figures 3.4 and 3.5). With regard to the effects of adult social partners, both models indicated that $5^{\text {th }}, 6^{\text {th }}$, and $7^{\text {th }}$ grade students who experienced their 
parents and teachers as more supportive also reported that they were more emotionally engaged in learning activities at both time points. That is, parent and teacher warm involvement each uniquely and positively predicted adolescents' emotional engagement across both models, over and above the effects of the other social partner. The cumulative effects of parents and teachers were not significantly different between $5^{\text {th }}, 6^{\text {th }}$, and $7^{\text {th }}$ grade students. As with behavioral engagement, both models also demonstrated the reciprocal effects of adolescents' emotional engagement on changes in adults' involvement over the school year. Across $5^{\text {th }}, 6^{\text {th }}$, and $7^{\text {th }}$ grades, students' emotional engagement with academic tasks positively predicted increases in their parents' and teachers' subsequent warm involvement.

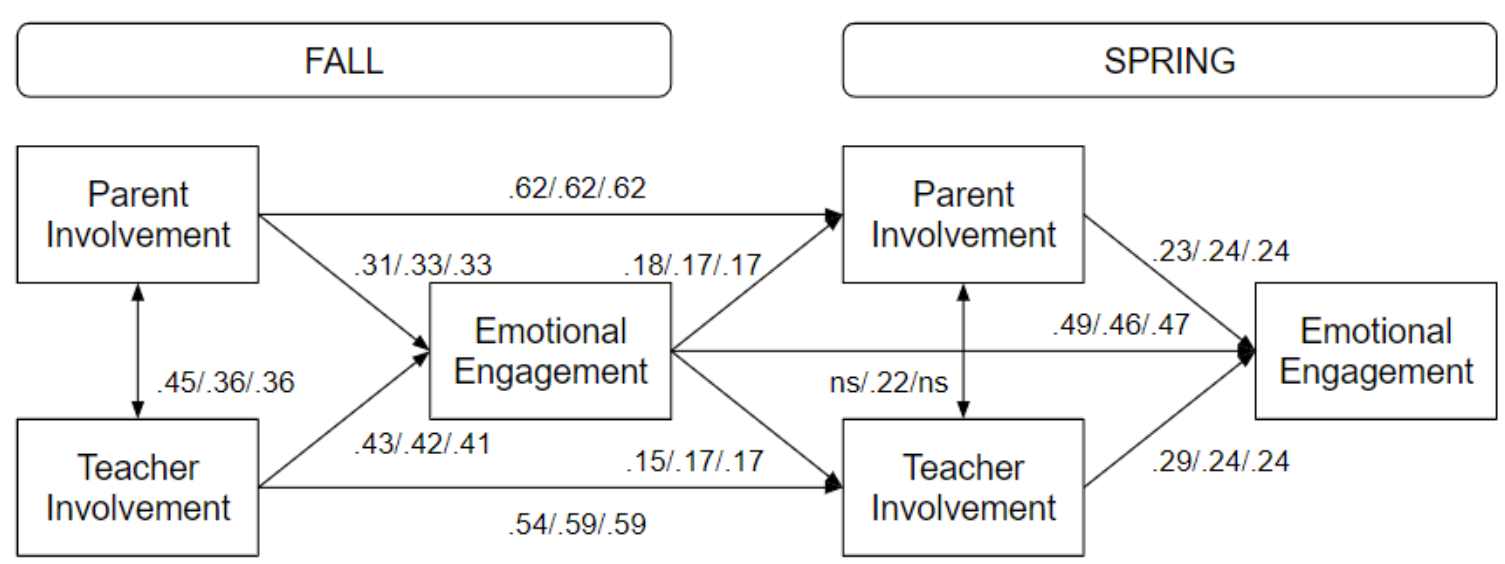

Figure 3.4. Constrained effects path model for emotional engagement. $5^{\text {th }} / 6^{\text {th }} / 7^{\text {th }}$ grade effects. All effects were standardized, and unless otherwise noted, significant at least at $p$ $<.10 . \chi^{2}(30)=48.26 p<.05 ; \mathrm{CFI}=.99, \mathrm{TLI}=.98, \mathrm{RMSEA}=.05, \mathrm{SRMR}=.04 .92 .1 \%$ of standardized correlation residuals were less than $|2.00|$. 


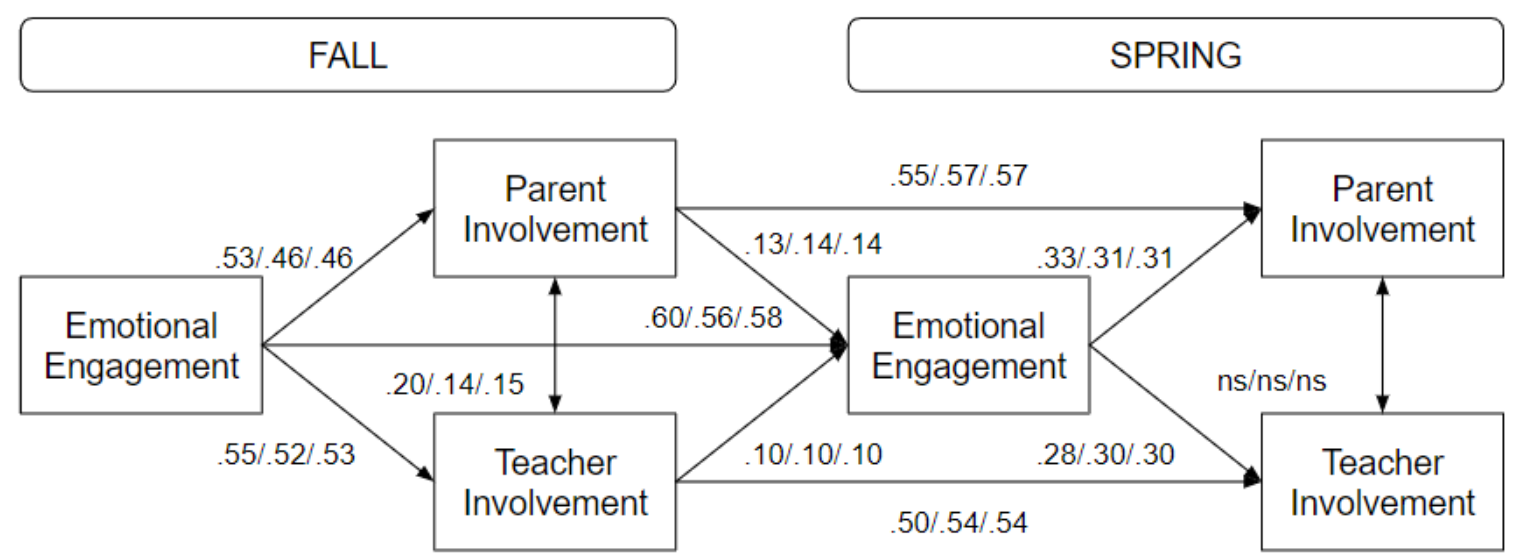

Figure 3.5. Constrained effects alternative path model for emotional engagement. $5^{\text {th }} / 6^{\text {th }} / 7^{\text {th }}$ grade effects. All effects were standardized, and unless otherwise noted, significant at least at $p<.10 . \chi^{2}(30)=46.83 p<.05 ; \mathrm{CFI}=.99, \mathrm{TLI}=.98, \mathrm{RMSEA}=.05$, $\mathrm{SRMR}=.04 .92 .1 \%$ of standardized correlation residuals were less than $|2.00|$.

When comparing the two models, there were differences in the magnitude of effects depending on which social partner was modeled as the leading independent variable. As expected, concurrent effects were stronger than predictions of change over time, even though both were significant in both models. Similar to behavioral engagement, parents' and teachers' warm involvement had stronger effects than adolescents' emotional engagement when adult social partners were the leading independent variables. On the other hand, adolescents exerted stronger effects on both parents and teachers when they were modeled as the driving force behind these relationships.

\section{Discussion}

The current study sought to explore the potential dynamics of motivational development by examining whether parents' and teachers' warm involvement exert cumulative effects on the development of adolescents' academic engagement, and 
whether adolescents' engagement plays a reciprocal role in shaping adults' continued involvement. As demonstrated in the path models above, consistent support for the cumulative effects of both parents and teachers was found. Across $5^{\text {th }}, 6^{\text {th }}$, and $7^{\text {th }}$ grades, parents and teachers each uniquely and positively predicted adolescents' behavioral and emotional engagement across the school year. In line with previous studies on the combined effects of parents and teachers (Brewster \& Bowen, 2004; Murray, 2009; Quin et al., 2017), this suggests that both of these key adult social partners are important in the development of students' engagement with academic tasks and challenges. Of note, when averaging the effects of parents and teachers across grades and models, teachers exerted slightly stronger effects on adolescents' behavioral and emotional engagement in fall (average $\beta=.41$ ) than did parents' (average $\beta=.32$ ), although this difference was not as pronounced by spring (teacher average $\beta=.25$ vs. parent average $\beta=.20$ ). This could be due to the proximity of teachers to the classroom environment where students are most commonly expressing their academic engagement with tasks and challenges, and in fact, our measures of academic engagement specifically focused on students' experiences in the classroom and at school. Nonetheless, the results demonstrate the importance of both parents and teachers to the development of adolescents' academic engagement.

With regard to the reciprocal effects of adolescents on their parents and teachers, consistent, positive results were found across grades and social partners. When $5^{\text {th }}, 6^{\text {th }}$, and $7^{\text {th }}$ grade adolescents were behaviorally and emotionally engaged with academic tasks and challenges, they perceived their parents and teachers as responding with continued warm support across the school year, whereas students who initially reported 
behavioral or emotional disaffection experienced their parents and teachers as withdrawing support over time. This pattern of results suggests that adolescents can exert feedback effects on their adult social partners, adding to the few studies that have previously documented such effects (Dumont et al., 2014; Skinner \& Belmont, 1993). Taken together, these models provide support for a reciprocal dynamic that over time could lead to either virtuous cycles involving increases in both adult involvement and adolescent academic engagement as they positively influence each other, or to vicious cycles as lack of adult support and student disaffection mutually amplify each other over time.

\section{Limitations and Future Directions}

There are several ways that the results from the current study can be used to guide future research. Methodologically, given that the current study consisted of predominantly White, middle class students, future work could examine these patterns of effects with a more diverse sample. Although many theories would posit that the importance of warm involvement on students' academic engagement is universal (e.g., self-determination theory, attachment theory, self-efficacy theory, etc.; Martin \& Dowson, 2009), nonetheless, future studies could test this assumption and determine if there are differential impacts of parents and teachers across diverse students. For example, for students' facing discrimination, economic hardships, or other adversities, warm support from parents and teachers may be even more important in promoting their continued engagement in school. 
With regard to measures, in order to mitigate common method bias from using the same reporter for all variables, future studies could incorporate additional sources of information about the constructs of interest (such as parent or teacher reports of their own involvement or teacher reports of adolescents' engagement). Further, future studies could more directly examine the effects of the switch in middle school from few to many different teachers. The current study employed the same set of items across all students, using the referent "my teacher." This allowed measures to be comparable across grades, but it also meant that $5^{\text {th }}$ grade students reported on a single teacher's warm involvement while $6^{\text {th }}$ and $7^{\text {th }}$ grade students, who had multiple teachers, were not directed to think about any particular teacher. Thus, it is unclear if $6^{\text {th }}$ and $7^{\text {th }}$ graders reported on the warm involvement from their homeroom teacher, favorite teacher, or an aggregate of their experiences across multiple teachers.

Finally, with regard to methodology, future studies could be improved by expanding beyond a single school year to look at the combined and reciprocal effects of parents, teachers, and adolescents across multiple school years. Longitudinal data would allow researchers to examine whether this reciprocal dynamic actually contributes to changes in engagement as adolescents transition from elementary to middle school, and to see whether adult supports (prior to and during the middle school transition) can predict differential trajectories of behavioral and emotional engagement.

Conceptually, future research could expand on the current study by including additional forms of support from social partners as well as additional social partners who might influence students' academic engagement. With regard to forms of support, the 
self-system process model of motivation, as one example, posits that in addition to warm involvement, provision of structure and autonomy support from social partners can also fuel students' behavioral and emotional engagement with academic tasks (Connell \& Wellborn, 1991; Hospel \& Galand, 2016; Jang, Reeve, \& Deci, 2010). While the current study incorporated two of the key contexts that shape adolescents' development and so improved upon previous research examining the effects of parents and teachers individually, there are still several other key social partners that influence adolescents' academic lives. Therefore, future studies should examine additional social partners such as peers (Juvonen, Espinoza, \& Knifsend, 2012; Kindermann, 2016; Wentzel \& Muenks, 2016), siblings (Tougas, Jutras, \& Bigras, 2016), and mentors (Holt, Bry, \& Johnson, 2008; Hurd \& Sellers, 2013).

While the current study provides support for the cumulative and reciprocal influences of parents, teachers, and adolescents, subsequent research could also explore the mechanisms behind these effects. For example, the self-system process model of motivation (Connell \& Wellborn, 1991) would posit that a sense of relatedness or connection to others is one conduit through which warm involvement from social partners supports adolescents' engagement with academic tasks and challenges. As a possible mechanism of reciprocal effects, parents and teachers might label adolescents as "motivated" or "unmotivated" based on their behavioral and emotional engagement, thus influencing adults' continued level of involvement.

\section{Implications}


The results of the current study offer fruitful information for future intervention work aimed at promoting adolescents' academic engagement during a time in which it often declines (Wigfield et al., 2015). Evidence for the cumulative effects of parents and teachers suggests that researchers should focus on both adults when designing interventions. If programs only focus on one social partner, for example teachers, these interventions will only optimize the engagement of those students who already are receiving warm support from the other social partner, parents. To fully allow for the optimization of adolescents' engagement with academic tasks and challenges, educational programs and practices need to promote the warm, supportive involvement of both parents and teachers. Given that parents and teachers respond to students' engagement creating a reciprocal dynamic, it is important that we intervene and ensure a virtuous cycle of involvement, engagement, and continued involvement as opposed to allowing vicious cycles of disaffection, withdrawal, and subsequent disaffection to develop. Such efforts will guarantee that students receive the cumulative support they need over the challenging transition to middle school. 


\section{Chapter 4: Study 2}

Parent and Teacher Warm Involvement, Sense of Relatedness, and Students' Academic Engagement: A Process Model of Motivation

An important goal for parents, teachers, and researchers is to optimize the development of student engagement with academic tasks (Wentzel, 1998; Wentzel \& Ramani, 2016), especially given the many positive outcomes associated with academic engagement, including students' attendance, retention, grades, achievement, and resilience (Christenson, Reschly, \& Wylie, 2012; Fredricks, Blumenfeld, \& Paris, 2004; Wigfield et al., 2015). In seeking to analyze the social factors that contribute to students' motivation and engagement in school, separate lines of research have demonstrated the beneficial effects of high-quality relationships and support from parents and teachers. For example, research on parents' warm, supportive involvement has found that when parents are emotionally supportive, responsive, and interested in their children's academic needs, their offspring are more motivated and academically engaged (Bempechat \& Shernoff, 2012; Upadyaya \& Salmela-Aro, 2013; Raftery et al., 2012; Grolnick, Friendly, \& Bellas, 2009). Similarly, work with teachers has demonstrated that when teachers are interested in their students and offer warmth and affection, their students are more engaged in learning (Pianta, Hamre, \& Allen, 2012; Quin, 2017; Roorda, Koomen, Spilt, \& Oort, 2011; Upadyaya \& Salmela-Aro, 2013; Wentzel, 2016; Wigfield et al., 2015). However, in previous research attempting to solve the puzzle of how to optimize student motivation, two important pieces have largely been missing: (1) an examination of the 
combined or simultaneous effects of both parents and teachers; and (2) an understanding of the mechanism through which parents' and teachers' involvement subsequently impacts students' academic engagement.

\section{Combined Effects of Parent and Teacher Involvement}

A few studies have begun to examine the combined effects of parent and teacher involvement on students' academic engagement, reflecting the more complex social ecologies in which students' development is embedded (Bronfenbrenner \& Morris, 1998). These studies can be seen as part of larger theoretical frameworks positing that the relationships students hold with a variety of social partners, such as parents and teachers, create "multiple worlds" (Phelan, Davidson, \& Cao, 1991; Phelan, Davidson, \& Yu, 1998), and that to fully understand student motivation and engagement, researchers may need to examine the effects of different kinds of social partners in combination (Wentzel, 1998).

Consistent with this premise, three studies have examined parent and teacher warm involvement in the same statistical model, and discovered that support from both social partners uniquely predicts students' engagement. More specifically, Brewster and Bowen (2004) found that both parent and teacher warm support positively and uniquely predicted Latino students' perceptions of school meaningfulness. In the same vein, Murray (2009) found that parent positive involvement and teacher closeness-trust both uniquely predicted $6^{\text {th }}, 7^{\text {th }}$, and $8^{\text {th }}$ grade Latino students' engagement. Finally, Quin, Hemphill, and Heerd (2017) discovered that parents' support for education and teachers' support for relatedness each uniquely predicted Australian students' emotional 
engagement. In other words, parents and teachers each seem to make a significant contribution in optimizing students' academic engagement, above and beyond the effects of the other. Given the paucity of research examining both parents and teachers, and the reliance of previous studies on data from a single time point, one goal of the current study was to determine the combined effects of parent and teacher involvement on changes in students' academic engagement across a single school year.

\section{Sense of Relatedness as a Mediator}

While recent work examining the combined effects of parents and teachers is promising, none of these studies of combined effects have attempted to explain the pathways through which involvement from both social partners simultaneously contributes to students' engagement, and whether these mediators are the same for both social partners. Drawing on previous research examining parents and teachers separately, the self-system process model of motivational development (Connell \& Wellborn, 1991) identifies likely mediators of the effects of parent and teacher involvement on student engagement. According to this model (see Figure 4.1), and the umbrella framework provided by self-determination theory (SDT; Ryan \& Deci, 2017), warm involvement from social partners supports students' need for relatedness or belonging, defined as students' basic desire to feel connected to others (Baumeister \& Leary, 1995). Consistent with the tenets of attachment theory (Bergin \& Bergin, 2009), as parents, teachers, and other social partners provide affection and warmth, show students that they care, and are interested in their lives, students are more likely to feel secure and that they belong and are connected to those around them. When students' need for relatedness is fulfilled, they 
are more willing to adopt the goals and values of these social partners and are more motivated to participate in the learning activities parents and teachers endorse. As a result, students are more likely to show behavioral and emotional engagement in the classroom. When students feel related and connected to their social partners, it fuels patterns of action characterized by energy, direction, and persistence with academic tasks and challenges. Thus, when students have secure, warm, interpersonal relationships with their parents and teachers, they will feel supported and explore, work hard, and cope well in school (Wentzel, 2016).

\section{Parents, Teachers CONTEXT} SELF ACTION $\rightarrow$ OUTCOMES

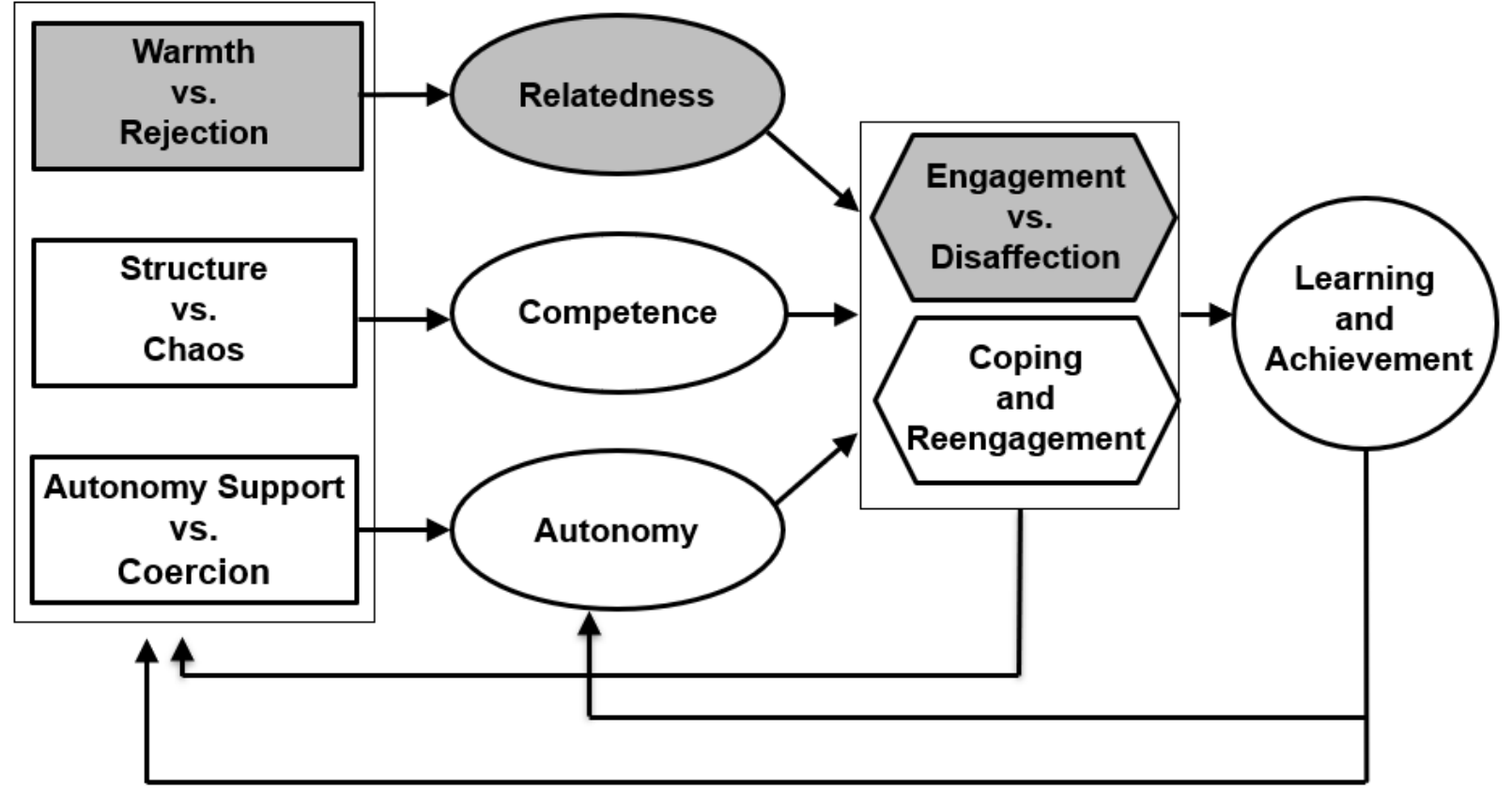

Figure 4.1. Process model account of involvement, relatedness, and academic engagement through the self-system process model of motivation (Connell \& Wellborn, 1991). 
Since previous research has mainly examined the effects of parents and teachers separately, it is not yet known whether both adult social partners' involvement has the same impact on students' sense of relatedness and subsequent academic engagement. Attachment research (Bergin \& Bergin, 2009) could suggest that parents, as secure bases for their children, would be of greater importance to students' sense of relatedness and belonging to others. However, as social partners most proximal to the educational context, teachers may have a larger impact on students' sense of relatedness and subsequent engagement with academic tasks in the classroom. For example, Duchesne and Larose (2007) found that parents' attachment quality was only indirectly related to grade 7 students' academic motivation through its effects on teachers' support. Or, it is possible that both parents and teachers are equally important to students' sense of relatedness as key adult social partners. Thus, another goal of the current study was to examine how parents' and teachers' warm involvement promotes students' academic engagement by fostering a sense of relatedness, and whether these mediation effects are similar across both social partners.

Moreover, previous studies have not yet examined whether the contributions or mediators of parent and teacher involvement shift as students approach and transition to middle school. Although research studying these social partners individually suggests that both parents and teachers continue to play important roles in their children's and students' motivation and engagement all across elementary and middle school, it is possible that the balance between parents and teachers shifts, or that the importance of relatedness as a mediator changes. It is also possible that these effects and pathways 
would be relatively consistent across age or grade groups, as would be suggested by the self-system process model and SDT which posit that relatedness is a fundamental psychological need across the entire lifespan and that both proximal and distal contexts play a role in whether this need is thwarted or fulfilled.

\section{Current Study}

The current study sought to examine the means through which parents' and teachers' warm involvement impact changes in students' academic engagement across the school year for students in late elementary and early middle school (grades 3-6; ages 8-13). The following four research questions were addressed:

1. Do parent and teacher warm involvement simultaneously predict changes in students' subsequent academic engagement?

2. Do parent and teacher warm involvement simultaneously predict students' sense of relatedness?

3. Does students' sense of relatedness explain the relations between parent and teacher warm involvement and changes in students' academic engagement?

4. Do these patterns of effects differ across school grades?

Based on previous research and the self-system process model of motivation, it was hypothesized that parent and teacher involvement would each positively and uniquely predict changes in students' engagement as well as their sense of relatedness to those around them. Further, it was anticipated that the positive relation between parent and teacher involvement and changes in students' engagement would be at least partially mediated through the pathway of students' feelings of relatedness and connection to 
others. There were no specific hypotheses for the last research question; however, the self-system process model of motivation would posit that this mediation path of involvement through relatedness to engagement would function similarly for students across all ages and grades (Connell \& Wellborn, 1991).

\section{Method}

\section{Participants}

Participants were $10113^{\text {rd }}(N=137)$ graders, ages 8 to $9(M=8.36) ; 4^{\text {th }}$ graders $(N=340)$, ages 9 to $11(M=10.69) ; 5^{\text {th }}$ graders $(N=169)$, ages 10 to $12(M=11.66)$; and $6^{\text {th }}$ graders $(N=365)$, ages 11 to $13(M=12.66)$. The majority of participants were White $(95 \%)$ and about half were female $(52.7 \%)$.

\section{Design and Procedure}

To examine these research questions, secondary data from a longitudinal study of students in an entire school district in upstate New York were analyzed. As part of a cohort-sequential design, the current study focused on survey data from $3^{\text {rd }}$ through $6^{\text {th }}$ grade students collected in the fall and spring of the second year of data collection.

\section{Measures}

All measures were rated on a 4 -point scale $(1=$ not at all true for me, $4=$ very true for me) and negative items were reverse-coded so higher scores represented higher levels of each construct.

Perceived parent warm involvement. Students rated their parents'supportive affection and attention in the fall across six items (Skinner, Johnson, \& Snyder, 2005; Fall: $\left.\alpha_{3}=.59, \alpha_{4}=.63, \alpha_{5}=.71, \alpha_{6}=.75\right)$, including "My parents know a lot about what 
is important to me in school" and "When I want to talk about school my parents take the time."

Perceived teacher warm involvement. Students rated their teachers' warm support and interest in the fall across seven items (Skinner \& Belmont, 1993; Fall: $\alpha_{3}=$ $\left..77, \alpha_{4}=.76, \alpha_{5}=.82, \alpha_{6}=.80\right)$, including "My teacher spends time with me" and "My teacher really cares about me."

Sense of relatedness. Students rated their feelings of belonging and connectedness to their mothers, fathers, and teachers in the spring with the same four items (Furrer \& Skinner, 2003; Spring: $\alpha_{3}=.79, \alpha_{4}=.68, \alpha_{5}=.53, \alpha_{6}=.69$ ): "When I'm with my , I feel accepted," "When I'm with my , I feel like someone special," "When I'm with my , I feel ignored" (reverse-coded), and "When I'm with my I feel unimportant" (reverse-coded).

Behavioral engagement. Students rated their active behavioral participation in the fall and spring with six items (Skinner, Kindermann, \& Furrer, 2009; Fall: $\alpha_{3}=.57$, $\alpha_{4}=.63, \alpha_{5}=.73, \alpha_{6}=.75$; Spring: $\left.\alpha_{3}=.67, \alpha_{4}=.74, \alpha_{5}=.74, \alpha_{6}=.73\right)$, such as "I participate in class discussion" and "When we start something new, I practically fall asleep" (reverse-coded).

Emotional engagement. Students rated their positive and negative academic emotions in the fall and spring with academic tasks with nine items (Skinner et al., 2009; Fall: $\alpha_{3}=.82, \alpha_{4}=.83, \alpha_{5}=.87, \alpha_{6}=.84$; Spring: $\left.\alpha_{3}=.86, \alpha_{4}=.86, \alpha_{5}=.87, \alpha_{6}=.85\right)$, including "When I'm in class, I feel happy" and "When I'm doing my work in class, I feel worried" (reverse-coded). 


\section{Results}

\section{Missing Data}

Missing data patterns and Little's missing completely at random (MCAR) test were analyzed (Little, 1988). For $3^{\text {rd }}$ grade students, missing data ranged from $10.2 \%$ to 32.8\% (Fall: $10.2 \%-16.1 \%$; Spring: $19.0 \%-32.8 \%$ ), and Little's MCAR test was not significant $\left(\chi^{2}(2499)=2530.61, p=.33\right)$, suggesting that the data was missing at random. For $4^{\text {th }}$ grade students, missing data ranged from $7.1 \%$ to $21.5 \%$ (Fall: $7.1 \%$ 12.4\% ; Spring: $14.4 \%-21.5 \%)$, and Little's MCAR test was significant $\left(\chi^{2}(5117)=\right.$ $5629.74, p<.001)$, suggesting that the data was not missing at random. For $5^{\text {th }}$ grade students, missing data ranged from $10.7 \%$ to $27.8 \%$ across all measures (Fall: $10.7 \%$ 21.3\%; Spring: $17.8 \%-27.8 \%)$, and Little's MCAR test was significant $\left(\chi^{2}(2674)=\right.$ $2814.04, p<.03)$, suggesting that the data was not missing at random. For $6^{\text {th }}$ grade students, missing data ranged from $10.1 \%$ to $29.6 \%$ across all measures (Fall: $10.1 \%$ 17.0\%; Spring: $19.7 \%-29.6 \%)$, and Little's MCAR test was significant $\left(\chi^{2}(4330)=\right.$ 4862.24, $p<.001)$, suggesting that the data was not missing completely at random. Given the mixture of missingness at random and not across grades, all subsequent analyses used full information maximum likelihood estimation.

\section{Descriptive Analyses}

Initial analyses were conducted to examine descriptive statistics and correlations between all variables of interest at each grade level (see Table 4.1). As expected, students' reports of parents' involvement, teachers' involvement, their own sense of relatedness to others, and their behavioral and emotional engagement with academic tasks 
were positively and significantly related across $3^{\text {rd }}, 4^{\text {th }}, 5^{\text {th }}$, and $6^{\text {th }}$ graders. Students who reported higher levels of warm involvement from parents and teachers also had stronger feelings of relatedness and behavioral and emotional engagement in class.

Table 4.1

Descriptive Statistics and Correlations among Variables for $3^{\text {rd }}, 4^{\text {th }}, 5^{\text {th }}$, and $6^{\text {th }}$ Grade Students

\begin{tabular}{|c|c|c|c|c|c|c|c|}
\hline Grade 3 & 1. & 2. & 3. & 4. & 5. & 6. & 7. \\
\hline 1. Parent Involve FA & 1.00 & & & & & & \\
\hline 2. Teacher Involve FA & $.50 * * *$ & 1.00 & & & & & \\
\hline 3. Behavioral Engage FA & $.52 * * *$ & $.58 * * *$ & 1.00 & & & & \\
\hline 4. Emotional Engage FA & $.49 * * *$ & $.58 * * *$ & $.58 * * *$ & 1.00 & & & \\
\hline 5. Relatedness SP & $.49 * * *$ & $.55 * * *$ & $.50 * * *$ & $.52 * * *$ & 1.00 & & \\
\hline 6. Behavioral Engage SP & $.55 * * *$ & $.33 * *$ & $.53 * * *$ & $.52 * * *$ & $.45^{* * *}$ & 1.00 & \\
\hline 7. Emotional Engage SP & $.37 * *$ & $.39 * * *$ & $.46^{* * *}$ & $.61 * * *$ & $.53 * * *$ & $.58 * * *$ & 1.00 \\
\hline$M(S D)$ & $3.28(.65)$ & $3.33(.71)$ & $3.02(.56)$ & $3.23(.56)$ & $3.29(.57)$ & $3.11(.61)$ & $3.21(.64)$ \\
\hline Grade 4 & 1. & 2. & 3. & 4. & 5. & 6. & 7. \\
\hline 1. Parent Involve FA & 1.00 & & & & & & \\
\hline nvolve FA & $.39 * * *$ & 1.00 & & & & & \\
\hline 3. Behavioral Engage FA & $.41 * * *$ & $.48 * * *$ & 1.00 & & & & \\
\hline 4. Emotional Engage FA & $.34 * * *$ & $.52 * * *$ & $.49 * * *$ & 1.00 & & & \\
\hline 5. Relatedness SP & $.42 * * *$ & $.42^{* * *}$ & $.40 * * *$ & $41^{* * *}$ & 1.00 & & \\
\hline 6. Behavioral Engage SP & $.39 * * *$ & $.36 * * *$ & $.60 * * *$ & $.32 * * *$ & $.51 * * *$ & 1.00 & \\
\hline 7. Emotional Engage SP & $.32 * * *$ & $.46 * * *$ & $.45 * * *$ & $.65 * * *$ & $.55^{* * * *}$ & $.59 * * *$ & 1.00 \\
\hline$M(S D)$ & $3.39(.57)$ & $3.30(.64)$ & $3.17(.52)$ & $3.27(.52)$ & $3.43(.58)$ & $3.26(.58)$ & $3.29(.57)$ \\
\hline Grade 5 & 1. & 2. & 3. & 4. & 5. & 6. & 7. \\
\hline 1. Parent Involve FA & 1.00 & & & & & & \\
\hline 2. Teacher Involve FA & $.36 * * *$ & 1.00 & & & & & \\
\hline 3. Behavioral Engage FA & $.42 * * *$ & $.54 * * *$ & 1.00 & & & & \\
\hline 4. Emotional Engage FA & $.50 * * *$ & $.44 * * *$ & $.53 * * *$ & 1.00 & & & \\
\hline 5. Relatedness SP & $.64 * * *$ & $.47 * * *$ & $.38 * * *$ & $.48^{* * * *}$ & 1.00 & & \\
\hline 6. Behavioral Engage SP & $.53 * * *$ & $.50 * * *$ & $.66^{* * * *}$ & $.43 * * *$ & $.50 * * *$ & 1.00 & \\
\hline 7. Emotional Engage SP & $.53^{* * *}$ & $.39^{* * *}$ & $.45^{* * *}$ & $.76^{* * *}$ & $.63 * * *$ & $.65^{* * *}$ & 1.00 \\
\hline$M(S D)$ & $3.56(.51)$ & $3.27(.67)$ & $3.32(.51)$ & $3.36(.54)$ & $3.51(.48)$ & $3.31(.56)$ & $3.29(.54)$ \\
\hline Grade 6 & 1. & 2. & 3. & 4. & 5. & 6. & 7. \\
\hline 1. Parent Involve FA & 1.00 & & & & & & \\
\hline 2. Teacher Involve FA & $.45 * * *$ & 1.00 & & & & & \\
\hline 3. Behavioral Engage FA & $.59 * * *$ & $.54 * * *$ & 1.00 & & & & \\
\hline 4. Emotional Engage FA & $.43^{* * *}$ & $47^{* * *}$ & $.59 * * *$ & 1.00 & & & \\
\hline 5. Relatedness SP & $.48^{* * *}$ & $.50 * * *$ & $.44 * * *$ & $.34 * * *$ & 1.00 & & \\
\hline 6. Behavioral Engage SP & $.43 * * *$ & $.42 * * *$ & $.65 * * *$ & $.45 * * *$ & $.50 * * *$ & 1.00 & \\
\hline 7. Emotional Engage SP & $.32 * * *$ & $.28 * * *$ & $.47 * * *$ & $.66^{* * * *}$ & $.48 * * *$ & $.58 * * *$ & 1.00 \\
\hline$M(S D)$ & $3.23(.64)$ & $3.00(67)$ & $3.14(.55)$ & $3.07(.55)$ & $3.29(.58)$ & $3.01(.55)$ & $3.00(.57)$ \\
\hline
\end{tabular}

Note . Involve $=$ Involvement, Engage $=$ Engagement, FA = Fall, $\mathrm{SP}=$ Spring. Shaded coefficients are cross-time stabilities from fall to spring.

$* * p<.01 * * * p<.001$ 


\section{Process Path Models}

To examine the research questions proposed for the current study, four mediation path models with structural equation modeling (SEM) were conducted, two each for the dependent variables of behavioral and emotional engagement. For each dependent variable, a multi-group path model differentiated by school grade with freely estimated parameters was conducted. This model was then compared to a multi-group path model with all loadings between grades constrained to be equal. Final model selection was based on model fit (CFI and TLI > .90, RMSEA and SRMR <.08; Hu \& Bentler, 1999) as well as model comparisons (chi-square difference tests, AIC, and BIC) shown in Table 4.2. These path models allowed us to determine across all four grades of students whether (a) both parent and teacher involvement in fall had positive and unique effects on changes in students' behavioral and emotional engagement from fall to spring; (b) both parent and teacher involvement in fall had positive and unique effects on students' sense of relatedness in spring; (c) if students' sense of relatedness to others in spring mediated the paths from parent and teacher involvement in fall to changes in student engagement across the school year; and (d) whether these effects differed across $3^{\text {rd }}, 4^{\text {th }}, 5^{\text {th }}$, and $6^{\text {th }}$ grade students.

As shown in Table 4.2, not only did the constrained effects models have better overall model fit, but model comparisons also favored them over the unconstrained effects models. For both behavioral and emotional engagement, best fitting statistical models were those that constrained the pattern of hypothesized effects to be equivalent 
across $3^{\text {rd }}, 4^{\text {th }}, 5^{\text {th }}$, and $6^{\text {th }}$ grades in this sample. Moving forward, we focus on the results from the constrained effects models.

Table 4.2

Model Comparisons for Unconstrained vs. Constrained Effects across Grades

\begin{tabular}{lllllllll}
\hline Model & CFI & TLI & RMSEA & SRMR & AIC & BIC & $\chi^{2}(\mathrm{df})$ & $\Delta \chi^{2}(\Delta \mathrm{df})$ \\
\hline \multicolumn{7}{l}{ Behavioral Engagement } \\
\hline Unconstrained & .98 & .79 & .17 & .03 & 6684.2 & 7057.2 & $31.82(4)^{* * *}$ & \\
Constrained & .98 & .97 & .07 & .05 & 6661.8 & 6946.4 & $45.33(22)^{* *}$ & $13.51(18)$ \\
\hline Emotional Engagement & & & & & & \\
\hline Unconstrained & .98 & .81 & .16 & .04 & 6580.2 & 6953.1 & $30.71(4)^{* * *}$ & \\
Constrained & .98 & .97 & .07 & .04 & 6559.7 & 6844.3 & $46.19(22)^{* *}$ & $15.48(18)$ \\
\hline
\end{tabular}

$* * p<.01 * * * p<.001$

Behavioral engagement. While parent and teacher involvement were each positively related to students' behavioral engagement (see Table 4.1), these direct effects were non-significant when modeling sense of relatedness as a mediator. Instead, parent and teacher involvement each exerted positive, indirect effects on students' behavioral engagement through their positive relation with students' sense of relatedness (see Figure 4.2). Regardless of grade in school, warm involvement from adults contributed to students' need for relatedness and connection to others, which in turn predicted increases in their active participation with academic tasks across the school year.

Emotional engagement. Similarly, relatedness mediated the relation between both parent and teacher warm involvement and changes in students' emotional engagement with academic tasks at school (see Figure 4.3). Regardless of grade in school, a sense of relatedness to others explained the positive relations between students' 
perceptions of parents' and teachers' warm, supportive involvement and changes across the school year in their emotional engagement with academic tasks and challenges. When students perceived their adult social partners as being supportive, affectionate, and attentive, they felt a sense of belonging and connection which predicted increases in their subsequent emotional enjoyment and interest in school. Therefore, it is through a sense of relatedness to others that parents' and teachers' warm involvement promotes changes in both students' behavioral and emotional engagement with academic tasks.

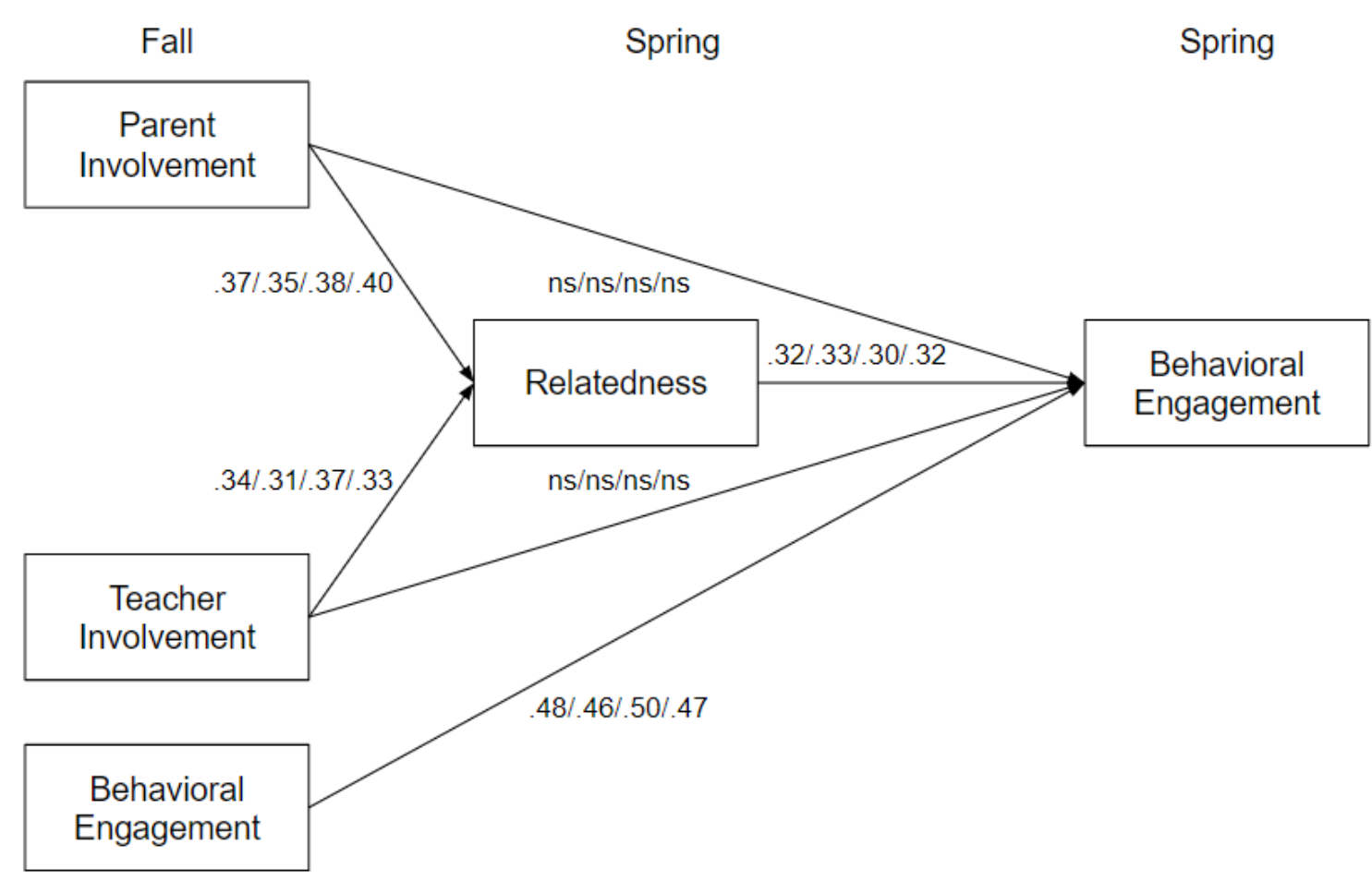

Figure 4.2. Constrained effects mediation model for behavioral engagement. $3^{\text {rd }} / 4^{\text {th }} / 5^{\text {th }} / 6^{\text {th }}$ grade effects. All effects were standardized, and unless otherwise noted, significant at $p<$ .001 . Indirect effects across all grades: $\beta_{\text {Parent Indirect }}=.12, p<.001, \beta_{\text {Teacher Indirect }}=.11, p$ $<.001$. 


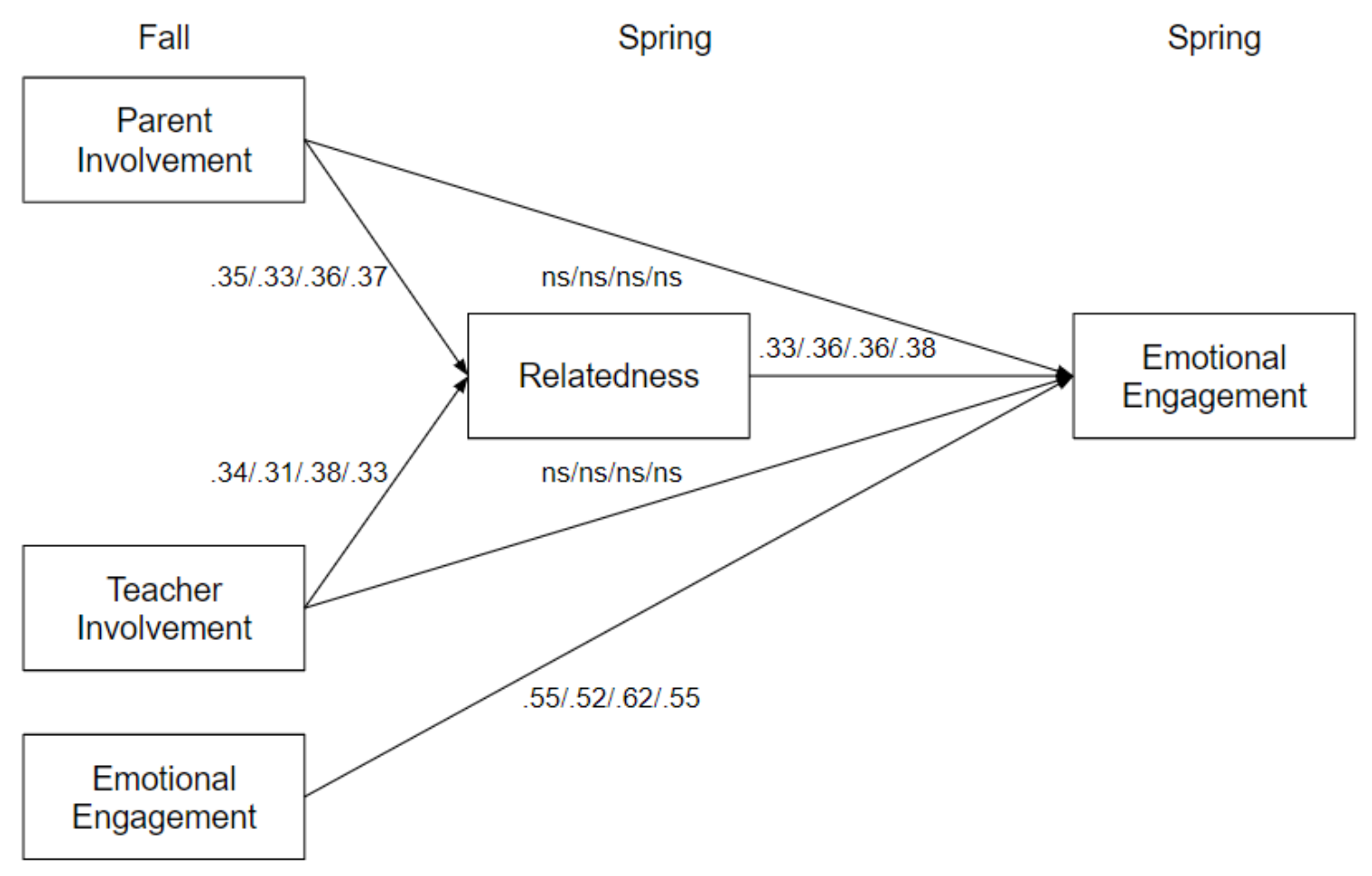

Figure 4.3. Constrained effects mediation model for emotional engagement. $3^{\text {rd }} / 4^{\text {th }} / 5^{\text {th }} / 6^{\text {th }}$ grade effects. All effects were standardized, and unless otherwise noted, significant at $p<$ .001 . Indirect effects across all grades: $\beta_{\text {Parent Indirect }}=.12, p<.001, \beta_{\text {Teacher Indirect }}=.11, p$ $<.001$.

\section{Discussion}

The current study adds to the growing body of research on the combined effects of parent and teacher warm involvement on the development of students' academic engagement by allowing us to understand the process by which parents and teachers impact their children and students. In this study, we found that both parents and teachers indirectly support improvements in student engagement through students' sense of relatedness and connectedness to their adult social partners across $3^{\text {rd }}, 4^{\text {th }}, 5^{\text {th }}$, and $6^{\text {th }}$ grades. By examining parents and teachers within the same path models, we were able to discern that the mediated effects were similar across both social partners. Further, these 
mediated effects can allow researchers to refine interventions aimed at facilitating student engagement by not only targeting both parents and teachers but also by focusing on their warm involvement to ensure that students' need for relatedness is fulfilled. Thus, the results of this study allow for a more holistic understanding of how to optimize student engagement.

\section{Limitations}

With regard to sample and design, future work can improve upon the current study by drawing on a more diverse sample, multiple reporters, and more time points. While the self-system process model of motivational development and SDT would suggest that the need for relatedness is universal (Connell \& Wellborn, 1991; Ryan \& Deci, 2017), nonetheless, future studies should determine whether this pattern of effects is similar in more diverse samples of students than those used in this study. For example, it is possible that the strength of these mediation effects might differ across students depending on whether or not their teachers come from the same racial and ethnic background (Bingham \& Okagaki, 2012). In addition, future work could explicitly examine differences between students in elementary versus middle school for these effects, thereby acknowledging the switch from one teacher to multiple teachers across the middle school transition. The current study used the same measure of teacher involvement across grades which simply specified "my teacher." Without more precise instructions for $6^{\text {th }}$ grade students, it is unclear whether they reported on their home room teacher, their favorite teacher, or all their teachers together. Further, the results of the current study might be impacted by common method bias given that student reports were 
the source for all constructs. To offset this, future studies could include multiple reporters, such as parent and teacher reports of their own involvement or observer reports of student engagement. Finally, the mediation results of this study could be strengthened by the use of more than two time points (e.g., warm involvement at time 1, relatedness at time 2, and academic engagement at time 3) across the school year and by examining how these effects unfold longitudinally across multiple school years.

\section{Future Directions}

While the current study is one of the first to try to explain how the combined effects of parents and teachers can optimize students' academic engagement, future studies could expand on this study in two ways. First, researchers could consider other potential mediators. For example, as pictured in Figure 1, the self-system process model of motivation and SDT also posit that students have needs for competence (e.g., sense of efficacy) and autonomy (e.g., sense of choice and voice; Connell \& Wellborn, 1991; Ryan \& Deci, 2017). Future work could examine whether the effects of parent and teacher involvement on engagement are mediated not only by students' sense of relatedness, but also their perceived competence and autonomy and whether the effects of social partners are differentially mediated by these three self-system processes.

Perhaps as the adults most proximal to the instructional process in the classroom, teachers will more strongly support students' sense of competence and subsequent engagement, while parents, who especially with their adolescent children are negotiating shifting power dynamics, will more strongly influence their offspring's sense of autonomy and continued engagement. Additional self-processes that might act as 
mediators between support from social partners and academic engagement include, but are not limited to, self-efficacy, expectancies and values, and achievement goals (Wigfield et al., 2015).

Bronfenbrenner's bioecological model suggests that individuals are embedded in multiple microsystem level contexts, interacting together both with (mesosystems) and without (exosystems) the developing individual and influenced by higher order societal, cultural, and historical influences (macrosystem and chronosystem; Bronfenbrenner \& Morris, 1998). While the current study incorporates two such social partners (parents and teachers) and microsystems (home and school), future research can better represent the complex social ecologies of students' academic lives by considering additional social partners and interactions between contexts. For example, in addition to parents and teachers, other social partners such as mentors, coaches, peers, and siblings offer warm support to students and can help to optimize their sense of belonging and engagement with academic tasks and challenges (Holt, Bry, \& Johnson, 2008; Hurd \& Sellers, 2013; Juvonen, Espinoza, \& Knifsend, 2012; Kindermann \& Skinner, 2009; Tougas, Jutras, \& Bigras, 2016; Wentzel \& Muenks, 2016). As well, the dynamic interactions between parents, teachers, peers, etc. in and outside of the classroom context may impact students' sense of self and continued engagement in school. It is possible that the multitude of effects from these various social partners might be cumulative in nature, where support from parents, teachers, and peers, for example, all positively predicts students' academic engagement (e.g., Furrer \& Skinner, 2003; King, 2015). Or perhaps these combined effects may be compensatory, where warm support from parents and teachers can buffer 
against peer disaffection. By more fully representing the complex, dynamic social ecologies where students live, we can better understand how to optimize their continued academic engagement.

\section{Educational Implications}

The findings from this study are important for educational practices and motivational interventions seeking to sustain student engagement, especially across the challenging transition to middle school. The significant mediating effect of a sense of relatedness from both parents' and teachers' warm involvement suggest that educational interventions should not only focus on students' academic skills and knowledge, but also expand outward to include social support and interpersonal relationships in and outside of the classroom. In line with this, educators and educational interventions can further expand outside of the classroom setting to seek the support of parents, mentors, coaches, peers, and siblings in students" other "multiple worlds" (Phelan, Davidson, \& Cao, 1991; Phelan, Davidson, \& Yu, 1998) in order to nurture a sense of relatedness and promote students' continued academic motivation and engagement. By acknowledging the importance of and fostering support from multiple social partners in these various ecological contexts, we can more effectively optimize students' academic lives. 


\section{Chapter 5: Discussion}

\section{Summary of Dissertation Studies}

The current dissertation sought to examine the combined effects of parent and teacher warm involvement on the development of adolescents' academic engagement through two separate studies. Study 1 utilized a series of path analyses to understand the dynamic effects of parents' and teachers' involvement and the reciprocal effects of adolescents' academic engagement. It was found that parents and teachers each exert positive, unique effects on $5^{\text {th }}, 6^{\text {th }}$, and $7^{\text {th }}$ grade adolescents' academic engagement across the school year and that adolescents' academic engagement reciprocally and positively influences parents' and teachers' subsequent involvement. Study 2 utilized mediation path analyses in order to examine the explanatory impacts of parent and teacher involvement on students' academic engagement through their sense of connection and relatedness to others. It was found that parents and teachers each exerted unique and cumulative effects on $3^{\text {rd }}, 4^{\text {th }}, 5^{\text {th }}$, and $6^{\text {th }}$ grade students' sense of relatedness as well as their academic engagement across the school year, suggesting that students' sense of belonging serves as at least one mediating pathway from adults' involvement.

\section{Strengths of the Current Studies}

There are several strengths offered by the two studies in this dissertation. First, both studies allowed a more complete view of the active interactions occurring between adolescents and their key adult social partners with regard to their own academic engagement. Both studies examined the dynamic effects of parent and teacher involvement for $3^{\text {rd }}$ through $7^{\text {th }}$ graders within a single school year. This is both a 
conceptual and methodological improvement upon previous research that has examined the individual effects of parents and teachers and neglected the multiple interacting systems in which adolescent development is embedded.

Second, both studies were longitudinal in design examining within school year changes from fall to spring and cross-sectional comparisons between elementary and middle school grades. This allowed for a further examination of temporal precedence and prediction of change over time, which were lacking in previous research on the combined effects of parents and teachers as well as an understanding of the shifting roles of parents and teachers with regard to adolescents' academic engagement. The few studies that have looked at these social partners and their impacts longitudinally have often done so through annual or biennial waves of assessment across school years, examining, for example, how parent and teacher support in $5^{\text {th }}$ grade predicts changes in students' motivation across $6^{\text {th }}, 7^{\text {th }}, 8^{\text {th }}$ grades and beyond (e.g., You, Hong, \& Ho, 2011). However, such designs do not take into account the changing contexts across school years, more specifically, that students switch teachers from school year to school year and the impacts of supports offered by a teacher in $5^{\text {th }}$ grade may be replaced by those offered by a teacher in $6^{\text {th }}$ grade. Examining longitudinal assessments within a given school year, as with these two studies, offsets this predicament while still allowing for the establishment temporal precedence. Further, the longitudinal design also enabled the analysis of mediating or explanatory effects between students' social ecologies in the fall and changes in their academic engagement from fall to spring in Study 2. Comparisons across grades also allowed insight into the changing contexts and support adolescents' 
face before, during, and after the middle school transition; however, these grade differences should not be conflated with grade changes.

Finally, Study 1 added to the few studies that have looked at the reciprocal or feedback effects of adolescents' academic engagement on their parents' and teachers' continued involvement (Dumont, Trautwein, Nagy, \& Nagengast, 2014; Skinner \& Belmont, 1993). To date, no studies of the combined effects of parents and teachers have tested for the agentic effects of adolescents on their adult social partners. By including these reciprocal effects, we can further understand the active nature of the development of adolescent academic engagement. The feedforward (parents and teachers impacting students) and feedback (students impacting parents and teachers) effects found in Study 1 suggest a dynamic process of motivational development. As adults offer sustenance, care, and interest in students' academic lives, this support fuels their behavioral and emotional engagement with academic work. Students' active enthusiasm, effort, and participation with academic tasks further engenders subsequent involvement, attention, and affection from parents and teachers, ideally creating a virtuous cycle of support and engagement.

\section{Limitations and Future Directions}

In spite of these strengths, these dissertation studies are not without their limitations. The scales used in both Study 1 and Study 2 were all self-reported by students. Utilizing scales from only one reporter makes all analyses susceptible to common method bias in which significant results may be due simply to the same reporter rating all variables of interest. Future studies should offset this by including multiple reporters, such as parent and teacher reports of their own involvement or teacher and 
observer ratings of students' engagement. Given that the relationships between parents and their children and teachers and their students both involve two social partners interacting and dynamically influencing each other, parent and teacher reports would offer additional insight into these back-and-forth exchanges. Not only would it be possible to compare adults and students on their perceptions of involvement and support offered and received, but multiple reporters would also allow a further examination of how parents and teachers experience and respond to adolescents' behavioral and emotional engagement. Since these relationships are shaped by visible social exchanges, reports from both adults and adolescents could be supplemented by observations conducted by trained coders, either in the home or in the classroom.

In addition, there were potential variations in the target individual for student reports of teacher involvement as they transitioned to middle school. In $3^{\text {rd }}, 4^{\text {th }}$, and $5^{\text {th }}$ grades, students had only one teacher and rated that teacher's warm involvement. In $6^{\text {th }}$ and $7^{\text {th }}$ grades, students entered middle school and had multiple teachers. Although all scales for teacher warm involvement remained the same across time points, no directions were specifically given to students for which teacher to rate in terms of their warm involvement. Therefore, conceptually it is not clear if middle school student reports were consistently targeting a home room teacher, a well-liked teacher, a disliked teacher, or an average of the students' teachers. By keeping the scale wording the same across grades, we were able to maintain measurement equivalence and comparability, although perhaps at the expense of measurement validity. 
Limitations are also evident in the data set analyzed across Study 1 and 2. While this data set included information on all students in an entire school district, it is almost 30 years old and largely consists of White students from working- and middle-class families. Therefore, the findings from both studies may lack generalizability to current day, diverse populations of adolescents. However, given previous research on the importance of parent and teacher warm involvement for adolescents' academic engagement and the multiple achievement motivation theories that highlight social support (e.g., self-determination theory, attachment theory, self-efficacy theory, etc.; Martin \& Dowson, 2009), it is likely that while the means through which warm involvement is communicated might change over time (i.e., technological advances both in the home and classroom), its importance will not.

Finally, although the studies in this dissertation improve upon individual effects research on parents or teachers, conceptually they are still lacking a fully dynamic model of multiple systems of adolescent development. For example, other forms of adult support have been shown to fuel adolescent academic engagement, such as parent and teacher structure (e.g., consistent rules, guidelines, and expectations) and autonomy support (e.g., encouraging adolescents' initiative, volition, and agency; Grolnick, Friendly, \& Bellas, 2009; Pomerantz \& Moorman, 2010). In addition, the multiple microsystems in which adolescents are embedded interact with each other at the mesosystem level of the bioecological model (Bronfenbrenner \& Morris, 1998), such as through parent-teacher conferences or parents attending school functions and assisting in the classroom. These direct interactions between parents and teachers were not captured 
in the current data set. Moreover, other key social partners and social ecologies are known or hypothesized to impact adolescents' academic engagement, including their peers (Juvonen, Espinoza, \& Knifsend, 2012; Kindermann \& Skinner, 2009; Wentzel \& Muenks, 2016), siblings (Tougas, Jutras, \& Bigras, 2016), and mentors (Holt, Bry, \& Johnson, 2008; Hurd, \& Sellers, 2013). As such, future studies should aim to test a more comprehensive model of adolescents' embedded social ecologies by including additional social partners, methods of support, and interactions between social partners.

\section{Implications for Interventions}

Based on evidence from both studies for the positive, combined effects of parents and teachers on adolescents, there are important implications for future interventions targeting adolescents' academic engagement. More specifically, interventions solely focusing on parents will only be effective in helping students reach their highest levels of engagement for adolescents who already have high levels of warm involvement from their teachers, while those targeting only teacher involvement will benefit students the most who already have involved parents. Therefore, since support from both parents and teachers is crucial to the optimal development of adolescents' academic engagement, it is imperative that intervention and prevention efforts focus on increasing the quality and quantity of both of these adult social partners' warm involvement. Given the cyclical nature of adult involvement and adolescents' engagement, interventions that target student engagement can also determine if, once improvements in engagement are established, these changes also lead to positive changes in parents' and teachers' warm support as a result, thus creating the potential for a virtuous cycle of support and 
engagement. In addition, the mediating effects of students' sense of relatedness supported in Study 2 pinpoint an additional target for future interventions. Supporting adolescents' need for relatedness - through parent and teacher warm involvement, a sense of belonging with peers and friends, or emotional security with other important social partners - is another means through which caregivers, educators, and researchers can fuel students' continued engagement in school, especially over the transition to middle school. Next Steps in Examining Students' Complex Social Ecologies

As a whole, developmental theory (i.e., Bronfenbrenner \& Morris, 1998; Connell \& Wellborn, 1991; Phelan et al., 1991; Ryan \& Deci, 2017; Wigfield et al., 2015), previous research (i.e., Brewster \& Bowen, 2004; Duchesne \& Larose, 2007; Murray, 2009; Perry et al., 2010; Quin et al., 2017), and the two studies in this dissertation stress the importance of examining the complex social ecologies of students' academic lives in order to optimize their academic development. If a goal of parents, educators, and researchers is to promote children's and students' academic engagement and motivation as they progress through school, then we not only need to acknowledge, represent, and understand adolescents' "multiple worlds" (Phelan et al., 1991), but we need to consider interactions between ecologies, shifts and developments within contexts, and the multiple leverage points offered by a more holistic view. To do so requires important next steps in future research to meet these goals and improve upon previous research focusing on the individual contributions of social partners and the few studies that examine their combined effects. 
Contextualized effects. As mentioned previously, there are multiple ways in which the combined effects of parents and teachers might be impacting students' academic development, including cumulative, differential mediation, and contextualized effects. While these two dissertation studies examined both cumulative and differential mediation effects, future work should also study the potential for contextualized or interactive effects in which the effect of one social partner depends on the other. Amplifying contextualized effects are possible wherein, for example, the extent to which support from parents impacts students' engagement depends on the strength of teachers' warm involvement. Therefore, students who experience warm involvement from teachers might benefit even more from parents' care and affection than students without teacher support. Another possible contextualized impact would be enabling effects in which the impact of a social partner is "turned on" or enabled by students' positive relationships with the other social partner. As an example, perhaps the positive impacts of teacher involvement on adolescents' academic engagement is only empowered when they already have warm support and care from their parents. Contextualized effects such as these are important to identify and understand in future research examining the combined effects of social partners on students' positive academic experiences.

Multiple, changing contexts. As mentioned above, a continued examination of multiple social partners is necessary given the multitude of adults, peers, and other sources of support that children and adolescents interact with across their academic lives and contexts. Further, these social partners and the ecologies they reside and move within are developing as well. Just as students are changing over time, their parents, teachers, 
peers, mentors, home contexts, and classroom and school settings are also changing. Some of these changes are due to shifts between contexts (i.e., the transition from single teacher, mastery-oriented elementary schools to multiple teachers, performance-oriented middle schools; Eccles \& Roeser, 2015) while others are due to inherent changes within contexts and social partners themselves (i.e., parents becoming more or less involved as adolescents strive toward independence; Spera, 2005; teacher-student relationships strengthening from fall to spring as relationships are established; shifts in home-life stability in response to economic changes and hardships; Evans, 2004). Given that these social partners and contexts are not static, theory and research will be stronger to the extent that they incorporate the potential for changing dynamics by integrating the chronosystem (i.e., change over time within an individual and across levels of their social ecology; Bronfenbrenner \& Morris, 1998) and utilizing longitudinal methodologies focused on change in the developing individual and their complex social ecologies over time.

Proximal interactions. Longitudinal methodologies examining students and their "multiple worlds" over multiple school years are not enough, however, to truly capture the dynamic, proximal interactions between social partners. Bronfenbrenner's bioecological model of development stresses that the long-term changes and stability seen in human development are in part a result of the proximal, back-and-forth, day-today interactions that occur between adolescents and their social partners (Bronfenbrenner \& Morris, 1998). Yet, annual longitudinal designs cannot effectively detect and capture these proximal processes between students and their parents, teachers, and other sources 
of support. Rather, shorter time-spans between measurement points can allow researchers a better look at the reciprocal dynamics of these proximal processes and changes across ecologies and social partners, as well as the potential mediational and explanatory pathways between involvement and engagement. As such, future work should collect longitudinal data quarterly, monthly, or even weekly throughout the school year to better focus on shifts within parents, teachers, homes, schools, etc. in addition to work examining yearly changes across school grades and transitions. This can allow researchers to identify and target "windows" of intervention and prevention in which warm involvement and social support might be most needed and effective in optimizing students' academic motivation. One such window might be the beginning of the school year when students are transitioning to new classroom contexts and first establishing teacher-student relationships; the strong supports and positive interactions laid down by parents and teachers in the first few weeks of the school year may have long-lasting impacts on students' continued engagement throughout the school year.

Higher-order contextual influences. These developing students and shifting social ecologies are further embedded in higher-order contexts of society, culture, history, and economics (Bronfenbrenner \& Morris, 1998). To better understand and design interventions applicable across communities, states, and cultures, it is important that future research draw on socio-cultural theories and measure macrosystem level impacts on students' academic lives and social partners (e.g., García Coll et al., 1996; Swanson et al., 2003; Vélez-Agosto, Soto-Crespo, Vizcarrondo-Oppenheimer, Vega-Molina, \& García Coll, 2017). Whether quantitatively through survey data or qualitatively through 
interviews and observations, future work can examine the impacts of poverty and access to socioeconomic resources; racial and ethnic differences between teachers and students; social partners' biases, stereotypes, and discrimination; cultural norms for parents' academic involvement; and historical shifts in parent-teacher, family-school communication and interactions on students' academic lives and "multiple worlds."

Person- and pattern-centered analyses. One way to better examine and understand these "multiple worlds" is through the use of person- or pattern-centered analyses, which examine patterns of relations among variables within individuals (Jung \& Wickrama, 2008). With such analyses, distinct subgroups or social ecologies of adolescents can be created or identified based on their combinations of parent and teacher involvement, allowing for a clearer representation of interaction effects without using a specific interaction term (i.e., parent support x teacher support). These analyses can offer a more complete representation of adolescents' actual social contexts - interacting with both parents and teachers on a daily basis - and have the potential to allow researchers to examine changes in these social ecologies across the adolescent years. For example, it is possible to track movement between kinds of social ecologies, and how transitioning from less supportive to more supportive social ecologies may promote motivational growth across the middle school grades.

Future research plans. In the face of these theoretical and methodological imperatives, as well as the rich opportunities for growth within this developing line of study, exciting future work awaits researchers. In my own future projects, I hope to address many of these suggestions for next steps. I plan to further examine children's and 
adolescents' complex social ecologies initially by continuing to study the combined influences of parents and teachers on students' academic lives as well as how interactions and communication between these two adult social partners impacts students' academic engagement. In addition to incorporating more meso- and exosystem contextual impacts (i.e., parent-teacher connections), I want to build upon these two dissertation studies by collecting both short- and long-term longitudinal data. I aim to better capture the dynamics between students and their social partners through quarterly collection timepoints within each school year, across three school years, and cross-sections of grades (e.g., data collected four times a year across $4^{\text {th }}, 5^{\text {th }}$, and $6^{\text {th }}$ grade students, each followed for a total of three school years). With this design, I hope to examine proximal interactions, longitudinal developmental changes, within vs. between school year differences, and long-term impacts for developing students as well as their changing social partners and shifting contexts. Further, in addition to warm involvement, I plan to measure parents' and teachers' structure, autonomy support, mindsets, and goal orientations as additional forms of support, reported by students, parents, and teachers. 


\section{References}

Anderman, E.M., \& Mueller, C.E. (2010). Middle school transitions and adolescent development. In J.L. Meece, \& J.S. Eccles (Eds.), Handbook of research on schools, schooling, and human development (pp. 198-215). New York, NY: Routledge.

Baltes, P.B., Reese, H.W., \& Nesselroade, J.R. (1977). Life-span developmental psychology: Introduction to research methods. Monterey, CA: Brooks/Cole.

Baumeister, R.F., \& Leary, M.R. (1995). The need to belong: Desire for interpersonal attachments as a fundamental human motivation. Psychological Bulletin, 117, 497-529.

Bempechat, J., \& Shernoff, D.J. (2012). Parental influences on achievement motivation and student engagement. In Handbook of research on student engagement (pp. 315-342). Springer US.

Bergin, C., \& Bergin, D. (2009). Attachment in the classroom. Educational Psychology Review, 21, 141-170.

Bingham, G.E., \& Okagaki, L. (2012). Ethnicity and student engagement. In Handbook of research on student engagement (pp. 65-95). Boston, MA: Springer.

Brewster, A.B., \& Bowen, G.L. (2004). Teacher support and the school engagement of Latino middle and high school students at risk of school failure. Child and Adolescent Social Work Journal, 21, 47-67.

Bronfenbrenner, U., \& Morris, P.A. (1998). The ecology of developmental processes. In W. Damon (Series Ed.) \& R.M. Lerner (Vol. Ed.), Handbook of child psychology: 
Vol 1: Theoretical models of human development (pp. 993-1028). New York: Wiley.

Chan, C.S., Rhodes, J.E., Howard, W.J., Lowe, S.R., Schwartz, S.E.O., \& Herrera, C. (2013). Pathways of influence in school-based mentoring: The mediating role of parent and teacher relationships. Journal of School Psychology, 51, 129-142.

Chouinard, R., Karsenti, T., \& Roy, N. (2007). Relations among competence beliefs, utility value, achievement goals, and effort in mathematics. British Journal of Educational Psychology, 77, 501-517.

Christenson, S.L., Reschly, A.L., \& Wylie, C. (Eds.). (2012). Handbook of Research on Student Engagement. New York: Springer.

Connell, J.P., Spencer, M.B., \& Aber, J.L. (1994). Educational risk and resilience in African-American youth: Context, self, action, and outcomes in school. Child Development, 65, 493-506.

Connell, J.P., \& Wellborn, J.G. (1991). Competence, autonomy and relatedness: A motivational analysis of self-system processes. In M. Gunnar \& L.A. Sroufe (Eds.), Minnesota Symposium on Child Psychology, Vol. 23: Self processes in development (pp. 43-77). Chicago, IL: University of Chicago Press.

Duchesne, S., \& Larose, S. (2007). Adolescent parental attachment and academic motivation and performance in early adolescence. Journal of Applied Social Psychology, 37, 1501-1521.

Dumont, H., Trautwein, U., Nagy, G., \& Nagengast, B. (2014). Quality of parental homework involvement: Predictors and reciprocal relations with academic 
functioning in the reading domain. Journal of Educational Psychology, 106, 144161.

Eccles, J.S., Midgley, C., Wigfield, A., Buchanan, C.M., Reuman, D., Flanagan, C., \& Mac Iver, D. (1993). Development during adolescence: the impact of stageenvironment fit on young adolescents' experiences in schools and in families. American Psychologist, 48, 90.

Eccles, J.S., \& Roeser, R.W. (2015). School and community influences on human development. In M.H. Boorstein \& M.E. Lamb (Eds.), Developmental Psychology: An Advanced Textbook. Sixth Edition. Hillsdale, NJ: Erlbaum.

Evans, G.W. (2004). The environment of childhood poverty. American Psychologist, 59, 77-92.

Fredricks, J.A., Blumenfeld, P.C., \& Paris, A.H. (2004). School engagement: Potential of the concept, state of the evidence. Review of Educational Research, 74, 59-109.

Furrer, C., \& Skinner, E. (2003). Sense of relatedness as a factor in children's academic engagement and performance. Journal of Educational Psychology, 95, 148-162.

García Coll, C., Lamberty, G., Jenkins, R., McAdoo, H.P., Crnic, K., Wasik, B.H., \& García, H.V. (1996). An integrative model for the study of developmental competencies in minority children. Child Development, 67, 1891-1914.

Gonzalez-DeHass, A.R., Willems, P.P., \& Holbein, M.F.D. (2005). Examining the relationship between parental involvement and student motivation. Educational Psychology Review, 17, 99-123. 
Grolnick, W.S., Friendly, R.W., \& Bellas, V.M. (2009). Parenting and children's motivation at school. Handbook of motivation at school (pp. 279-300). New York, NY: Routledge.

Holt, L.J., Bry, B.H., \& Johnson, V.L. (2008). Enhancing school engagement in at-risk, urban minority adolescents through a school-based, adult mentoring intervention. Child \& Family Behavior Therapy, 30, 297-318.

Hospel, V., \& Galand, B. (2016). Are both classroom autonomy support and structure equally important for students' engagement? A multilevel analysis. Learning and Instruction, 41, 1-10.

Hu, L., \& Bentler, P.M. (1999). Cutoff Criteria for Fit Indexes in Covariance Structure Analysis: conventional criteria versus new alternatives. Structural Equation Modeling, 6, 1-55.

Hurd, N.M, \& Sellers, R.M. (2013). Black adolescents' relationships with natural mentors: Associations with academic engagement via social and emotional development. Cultural Diversity and Ethnic Minority Psychology, 19, 76-85.

Jang, H., Reeve, J., \& Deci, E.L. (2010). Engaging students in learning activities: It is not autonomy support or structure but autonomy support and structure. Journal of Educational Psychology, 102, 588.

Jung, T., \& Wickrama, K.A.S. (2008). An introduction to latent growth analysis and growth mixture modeling. Social and Personality Psychology Compass, 2, 302317. 
Juvonen, J., Espinoza, G., \& Knifsend, C. (2012). The role of peer relationships in student academic and extracurricular engagement. In S. Christenson, A. Reschly, \& C. Wylie (Eds.), Handbook of Research on Student Engagement (pp. 387-401). New York: Springer Science.

Kindermann, T.A. (2016). Peer group influences on students' academic motivation. Handbook of Social Influences in School Contexts: Social-Emotional, Motivation, and Cognitive Outcomes, 31-47.

Kindermann, T.A., \& Skinner, E.A. (2009). How do naturally existing peer groups shape children's academic development during sixth grade? International Journal of Developmental Science, 3, 27-38.

King, R. B. (2015). Sense of relatedness boosts engagement, achievement, and wellbeing: A latent growth model study. Contemporary Educational Psychology, 42, 26-38.

Little, R.J. (1988). A test of missing completely at random for multivariate data with missing values. Journal of the American Statistical Association, 83(404), 11981202.

Martin, A.J., \& Dowson, M. (2009). Interpersonal relationships, motivation, engagement, and achievement: Yields for theory, current issues, and educational practice. Review of Educational Research, 79, 327-365.

Murray, C. (2009). Parent and teacher relationships as predictors of school engagement and functioning among low-income urban youth. Journal of Early Adolescence, 29, 376-404. 
Noddings, N. (1992). The challenge to care in schools: An alternative approach to education. New York: Teachers College Press.

Nurmi, J-E. (2012). Students' characteristics and teacher-child relationships in instruction: A meta-analysis. Educational Research Review, 7, 177-197.

Perry, J.C., Liu, X., \& Pabian, Y. (2010). School engagement as a mediator of academic performance among urban youth: The role of career preparation, parental career support, and teacher support. The Counseling Psychologist, 38, 269-295.

Phelan, P., Davidson, A.L., \& Cao, H.T. (1991). Students' multiple worlds: Negotiating the boundaries of family, peer, and school cultures. Anthropology \& Education Quarterly, 22, 224-250.

Phelan, P., Davidson, A.L., \& Yu, H.C. (1998). Adolescents' worlds: Negotiating family, peers, and school. Teachers College Press.

Pianta, R.C., Hamre, B.K., \& Allen, J.P. (2012). Teacher-student relationships and engagement: Conceptualizing, measuring, and improving the capacity of classroom interactions. In Handbook of research on student engagement (pp. 365386). Springer US.

Pomerantz, E.M., \& Moorman, E.A. (2010). Parents' involvement in children's schooling. In J.L. Meece, \& J.S. Eccles (Eds.), Handbook of research on schools, schooling, and human development (pp. 398-416). New York, NY: Routledge.

Quin, D. (2017). Longitudinal and contextual associations between teacher-student relationships and student engagement: A systematic review. Review of Educational Research, 87, 345-387. 
Quin, D., Hemphill, S.A., \& Heerde, J.A. (2017). Associations between teaching quality and secondary students' behavioral, emotional, and cognitive engagement in school. Social Psychology of Education, 20, 807-829.

Raftery, J.N., Grolnick, W.S., \& Flamm, E.S. (2012). Families as facilitators of student engagement: Toward a home-school partnership model. In Handbook of research on student engagement (pp. 343-364). Springer US.

Roorda, D.L., Koomen, H.M.Y., Spilt, J.L., \& Oort, F.J. (2011). The influence of affective teacher-student relationships on students' school engagement and achievement: A meta-analytic approach. Review of Educational Research, 81, 493-529.

Ryan, R.M., \& Deci, E.L. (2017). Self-determination theory: Basic psychological needs in motivation, development, and wellness. New York, NY: Guilford Publications.

Skinner, E.A. (2016). Engagement and disaffection as central to processes of motivational resilience development. In K. Wentzel \& D. Miele (Eds.), Handbook of motivation in school, Malwah, NJ: Erlbaum.

Skinner, E.A., \& Belmont, M.J. (1993). Motivation in the classroom: Reciprocal effects of teacher behavior and student engagement across the school year. Journal of Educational Psychology, 85, 571-581.

Skinner, E.A., Johnson, S.J., \& Snyder, T. (2005). Six dimensions of parenting: A motivational model. Parenting: Science and Practice, 2, 175-235.

Skinner, E.A., Kindermann, T.A., Connell, J.P., \& Wellborn, J.G. (2009). Engagement and disaffection as organizational constructs in the dynamics of motivational 
development. In K. Wentzel \& A. Wigfield (Eds.), Handbook of motivation in school (p. 223-246). Malwah, NJ: Erlbaum.

Skinner, E.A., Kindermann, T.A., \& Furrer, C. (2009). A motivational perspective on engagement and disaffection: Conceptualization and assessment of children's behavioral and emotional participation in academic activities in the classroom. Educational and Psychological Measurement, 69, 493-525.

Skinner, E.A., \& Pitzer, J.R. (2012). Developmental dynamics of student engagement, coping, and everyday resilience. In Handbook of research on student engagement (pp. 21-44). Springer US.

Smetana, J.G., Campione-Barr, N., \& Metzger, A. (2006). Adolescent development in interpersonal and societal contexts. Annual Review of Psychology, 57, 255-284.

Spera, C. (2005). A review of the relationship among parenting practices, parenting styles, and adolescent school achievement. Educational Psychology Review, 17, 125-146.

Steinberg, L., \& Morris, A.S. (2001). Adolescent development. Annual review of Psychology, 52, 83-110.

Swanson, D.P., Spencer, M.B., Harpalani, V., Dupree, D., Noll, E., Ginzgurg, S., \& Seaton, G. (2003). Psychosocial development in racially and ethnically diverse youth: Conceptual and methodological challenges in the $21^{\text {st }}$ century. Development and Psychopathology, 15, 743-771. 
Tougas, A-M., Justras, S., \& Bigras, M. (2016). Types and influence of social support on school engagement of young survivors of leukemia. The Journal of School Nursing, 32, 281-293.

Upadyaya, K., \& Salmela-Aro, K. (2013). Development of school engagement in association with academic success and well-being in varying contexts: A review of empirical research. European Psychologist, 18, 136-147.

Vélez-Agosto, N.M., Soto-Crespo, J.G., Vizcarrondo-Oppenheimer, M., Vega-Molina, S., \& García Coll, C. (2017). Bronfenbrenner's bioecological theory revision: Moving culture from the macro into the micro. Perspectives on Psychological Science, 12, 900-910.

Wentzel, K.R. (1997). Student motivation in middle school: The role of perceived pedagogical caring. Journal of Educational Psychology, 89, 411-419.

Wentzel, K.R. (1998). Social relationships and motivation in middle school: The role of parents, teachers, and peers. Journal of Educational Psychology, 90, 202-209.

Wentzel, K.R. (2010). Students' relationships with teachers. In J.L. Meece, \& J.S. Eccles (Eds.), Handbook of research on schools, schooling, and human development (pp. 75-91). New York, NY: Routledge.

Wentzel, K. (2016). Teacher-student relationships. In K.R. Wentzel \& D.B. Miele (Eds.), Handbook of motivation in school 2nd edition (pp. 211-230). NY: Routledge.

Wentzel, K.R., \& Muenks, K. (2016). Peer influences on students' motivation, academic achievement, and social behavior. In K.R. Wentzel \& G.B. Ramani (Eds.), 
Handbook of Social Influences in School Contexts: Social-Emotional, Motivation, and Cognitive Outcomes (pp. 13-30). New York, NY: Routledge. Wentzel, K.R., \& Ramani, G.B. (Eds.). (2016). Handbook of social influences in school contexts: Social-emotional, motivation, and cognitive outcomes. New York, NY: Routledge.

Wigfield, A., Eccles, J.S., Fredericks, J.A., Simpkins, S., Roeser, R.W., \& Schiefele, U. (2015). Development of achievement motivation and engagement. In R.M. Lerner \& M. Lamb (Eds.), Handbook of Child Psychology and Developmental Science (pp. 657-700). New York: Wiley.

You, S., Hong, S., \& Ho, H-Z. (2011). Longitudinal effects of perceived control on academic achievement. The Journal of Educational Research, 104, 253-266. 


\section{Appendix A: Measures}

\begin{tabular}{|c|c|}
\hline Measure & Items \\
\hline $\begin{array}{l}\text { Student-Report Parent } \\
\text { Involvement }\end{array}$ & $\begin{array}{l}\text { 1. My parents know a lot about what's important to me. } \\
\text { 2. My parents know a lot about what is important to me in school. } \\
\text { 3. My parents don't know a lot about what goes on for me. } \\
\text { 4. My parents don't know a lot about what happens to me in } \\
\text { school. } \\
\text { 5. Sometimes I think my parents don't care what goes on for me. } \\
\text { 6. Sometimes I think my parents don't care about what goes on } \\
\text { for me in school. } \\
\text { 7. When I want to talk, my parents take the time to listen. } \\
\text { 8. When I want to talk about school my parents take the time. } \\
\text { 9. My parents don't seem to have enough time for me. } \\
\text { 10. My parents are too busy to hear about my school day. }\end{array}$ \\
\hline $\begin{array}{l}\text { Student-Report Teacher } \\
\text { Involvement }\end{array}$ & $\begin{array}{l}\text { 1. My teacher spends time with me. } \\
\text { 2. My teacher talks with me. } \\
\text { 3. My teacher likes me. } \\
\text { 4. My teacher really cares about me. } \\
\text { 5. My teacher doesn't seem to enjoy having me in her class. } \\
\text { 6. My teacher knows me well. } \\
\text { 7. My teacher just doesn't understand me. }\end{array}$ \\
\hline $\begin{array}{l}\text { Student-Report } \\
\text { Relatedness to Mother, } \\
\text { Father, Teacher }\end{array}$ & $\begin{array}{l}\text { 1. When I'm with my __ I feel accepted. } \\
\text { 2. When I'm with my _ I feel like someone special. } \\
\text { 3. When I'm with my___ I feel ignored. } \\
\text { 4. When I'm with my I I feel unimportant. }\end{array}$ \\
\hline $\begin{array}{l}\text { Student-Report Behavioral } \\
\text { Engagement }\end{array}$ & $\begin{array}{l}\text { 1. The first time my teacher talks about a new topic, I listen very } \\
\text { carefully. } \\
\text { 2. My mind wanders when my teacher starts a new topic. } \\
\text { 3. I try very hard in school. } \\
\text { 4. I participate in class discussions. } \\
\text { 5. In class, I try to do just enough to get by. } \\
\text { 6. When we start something new, I practically fall asleep. }\end{array}$ \\
\hline $\begin{array}{l}\text { Student-Report Emotional } \\
\text { Engagement }\end{array}$ & $\begin{array}{l}\text { 1. When we start something new in school, I feel interested. } \\
\text { 2. When we start something new in school, I feel worried. } \\
\text { 3. When I'm working on my classwork, I feel nervous. } \\
\text { 4. When I'm doing my work in class, I feel worried. } \\
\text { 5. When I'm in class, I feel good. } \\
\text { 6. When I'm in class, I feel sad. } \\
\text { 7. When I'm in school, I feel happy. } \\
\text { 8. When I'm in school, I feel bad. } \\
\text { 9. When I'm in school, I feel terrible. }\end{array}$ \\
\hline
\end{tabular}

